\title{
Poligoni Multiflori Radix enhances osteoblast formation and reduces osteoclast differentiation
}

\author{
SANG-YONG HAN, KYUNG-HEE LEE and YUN-KYUNG KIM \\ Department of Herbal Medicine, College of Pharmacy, Wonkwang Oriental Medicines Research Institute, \\ Wonkwang University, Iksan, Jeonbuk 54538, Republic of Korea
}

Received October 18, 2017; Accepted March 22, 2018

DOI: $10.3892 /$ ijmm.2018.3603

\begin{abstract}
Poligoni Multiflori Radix (PMR) is a traditional Korean medicinal herb that is known to have various pharmacological effects, including antihyperlipidemic, anticancer, and anti-inflammatory effects. However, the effects of PMR on bone metabolism have not been elucidated to date. The present study aimed to investigate the in vitro and in vivo effect of PMR water extract on the regulation of osteoblast and osteoclast activity. Effects of PMR water extract on receptor activator of nuclear factor-kB ligand (RANKL)-induced osteoclast differentiation and survival of mouse bone marrow macrophages (BMMs) obtained from femurs were investigated by tartrate-acid resistant acid phosphatase (TRAP)-positive cells and XTT assay. Expression of osteoclast-related genes was assayed by western blot analysis and reverse transcription-quantitative polymerase chain reaction. Additionally, the effects of PMR water extract on osteoblastic proliferation and differentiation were investigated by alkaline phosphatase (ALP) activity assay, alizarin red staining, and levels of mRNA encoding known osteoblast markers. Furthermore, the effects of PMR water extract on lipopolysaccharide (LPS)-induced bone loss were examined in a mouse model. PMR inhibited RANKL-induced osteoclast differentiation of BMMs in a dose-dependent manner without significant cytotoxicity, and suppressed expression of the main osteoclast differentiation markers Fos proto-oncogene and nuclear factor of activated T-cell. In addition, PMR decreased the mRNA expression levels of NFATc1 target genes, including TRAP, osteoclast-associated receptor, ATPase $\mathrm{H}^{+}$transporting, lysosomal $38 \mathrm{kDa}$ V0 subunit d2, and Cathepsin K. These inhibitory effects were mediated by the p38 and extracellular signal-regulated kinase/nuclear factor- $\kappa B$ pathway. Simultaneously, PMR enhanced the differentiation of primary osteoblasts, and increased the mRNA
\end{abstract}

Correspondence to: Professor Yun-Kyung Kim, Department of Herbal Medicine, College of Pharmacy, Wonkwang University, 460 Iksandae Road, Iksan, Jeonbuk 54538, Republic of Korea E-mail: hestia@wonkwang.ac.kr

Key words: Poligoni Multiflori Radix, osteoporosis, osteoclast, osteoblast expression of runt-related transcription factor 2, ALP, osterix, and osteocalcin. Notably, PMR improved LPS-induced trabecular bone loss in mice. Collectively, the present findings demonstrated that PMR may regulate bone remodeling by reducing osteoclast differentiation and stimulating osteoblast formation. These results suggest that PMR may be used for the treatment of bone diseases, such as osteoporosis and rheumatoid arthritis.

\section{Introduction}

Bone remodeling involves the resorption of old bone by osteoclasts and the formation of new bone by osteoblasts. Normal bone physiology requires a balance between the coupled processes of bone resorption and bone formation (1). In these processes, osteocytes including osteoblasts and osteoclasts are involved in the development, growth, and remodeling of bones. Disturbance in the balance of the remodeling process results in osteopenic disorders, including osteoporosis, rheumatoid arthritis and Paget's disease (2).

Regulation of bone remodeling occurs through multiple mechanisms that ultimately converge at the interaction of osteoclasts or their precursors with osteoblasts and bone marrow stromal cells. Osteoblasts are the bone-lining cells that are responsible for the production of bone matrix components and minerals during bone formation (3). They are regulated by various transcription factors, including runt-related transcription factor 2 (Runx2), osterix and $\beta$-catenin (4).

Osteoclast precursors, such as bone marrow-derived macrophages, express the receptors for macrophage colony stimulating factor (M-CSF) and for receptor activator of nuclear factor-kB ligand (RANKL), and differentiate into osteoclasts in the presence of M-CSF and RANKL expressed by osteoblasts (5). RANKL/receptor activator of nuclear factor-kB (RANK) signaling induces osteoclast differentiation and activation via various transcription factors, such as nuclear factor (NF)- $\kappa \mathrm{B}$, Fos proto-oncogene (c-Fos), and nuclear factor of activated T-cell (NFATc1) (6,7). c-Fos is an essential factor for the activation of NFATc1, which is a master regulator of RANKL-induced osteoclast differentiation; it regulates the expression of osteoclast-specific genes, including tartrate-acid resistant acid phosphatase (TRAP), Cathepsin K, Atp6v0d2, and osteoclast-associated receptor (OSCAR) (8). 
Polygoni Multiflori Radix (PMR) is the root of Polygonum multiflorum Thunb., and it is widely used in East Asia. PMR exhibits a variety of pharmacological effects, including acetylcholinesterase inhibitory activity, neuroprotective, antioxidant, immunomodulatory, antihyperlipidemic, anticancer, anti-inflammatory and hepatoprotective activities (9). PMR is used in Korean medicine to treat bone diseases by balancing the functions of osteoblasts and osteoclasts. Specifically, water extract of PMR exhibits antiosteoporotic efficacy in ovariectomized (OVX)-induced osteoporosis in mice $(10,11)$. However, the exact signaling mechanism that leads to PMR-mediated bone remodeling and osteoclast/osteoblast differentiation remains unclear. In the present study, the effects of PMR on osteoclast differentiation were investigated in RANKL-treated bone marrow-derived macrophages (BMMs) and in ascorbic acid/ $\beta$-glycerophosphate (AA/ $\beta$-GP)-induced osteoblast differentiation. In addition, the inhibitory effect of PMR was investigated in an animal model of lipopolysaccharide (LPS)-induced bone loss to evaluate the in vivo efficacy of PMR.

\section{Materials and methods}

Reagents. PMR was purchased from Omniherb Corporation (Daegu, Korea; Fig. 1). $\alpha$-minimum essential medium $(\alpha-M E M)$, fetal bovine serum (FBS), and antibiotics were purchased from Gibco (Thermo Fisher Scientific, Inc., Waltham, MA, USA). The XTT assay kit was purchased from Roche Diagnostics GmbH (Mannheim, Germany). Human recombinant M-CSF and RANKL were purchased from PeproTech EC, Ltd. (London, UK). Antibodies against c-Fos (1:1,000 dilution; cat. no. SC-7202), NFATc1 (1:1,000 dilution; cat. no. SC-7294) $\beta$-actin (1:1,000 dilution; cat. no. SC-47778), phosphorylated (p-) SMAD family member (Smad) 1/5/8 (1:1,000 dilution; cat. no. SC-12353), and total Smad1/5/8 (1:1,000 dilution; cat. no. SC-6031-R), were purchased from Santa Cruz Biotechnology, Inc. (Dallas, TX, USA). Antibodies against p-extracellular signal-regulated kinase (ERK; 1:1,000 dilution; cat. no. 4370), ERK (1:1,000 dilution; cat. no. 9102), p-c-Jun N-terminal kinase (JNK; 1:1,000 dilution; cat. no. 9251), JNK (1:1,000 dilution; cat. no. 9252), p-p38 (1:1,000 dilution; cat. no. 9211), p38 (1:1,000 dilution; cat. no. 9212), p-inhibitor of $\kappa \mathrm{B}$ (IкB; 1:1,000 dilution; cat. no. 2859), ІкB (1:1,000 dilution; cat. no. 4812), p-p65 NF- $\mathrm{B}$ (1:1,000 dilution; cat. no. 3033), and p65 NF- $\mathrm{KB}$ (1:1,000 dilution; cat. no. 8242) were purchased from Cell Signaling Technology Inc. (Beverly, MA, USA). Ascorbic acid (AA) and $\beta$-glycerophosphate ( $\beta$-GP) were purchased from Sigma-Aldrich (Merck KGaA, Darmstadt, Germany).

Mice. Five-week-old male ICR mice were purchased from Samtako Bio, Inc. (Osan, Korea). Mice were housed in a laminar air-flow room maintained at a temperature of $22-24^{\circ} \mathrm{C}$ and a reactive humidity of $55-60 \%$ with a 12 -h light/dark cycle. All experiments were performed in accordance with the guidelines of and approved by the Institutional Animal Care and Use Committee of Wonkwang University (approval no. WKU15-143).

Preparation of PMR. Preparation of PMR water extract was conducted following the extraction protocol of Korean

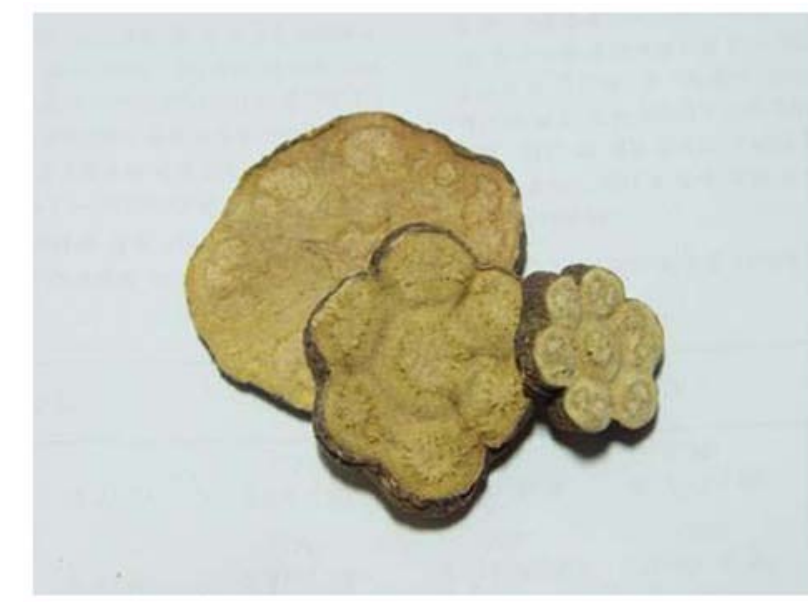

Figure 1. Photograph of PMR used in the present study. In Korea, PMR is frequently confused with other herb with similar Korean name, Cynanchum wilfordii Radix. PMR, Polygoni Multiflori Radix.

Plant Extract Bank (Cheongju, Korea). PMR was dissected into small pieces, placed in distilled water for $30 \mathrm{~min}$, and then boiled using Glas-Col heating mantle (Glas-Col LLC, Terre Haute, IN, USA) for $2 \mathrm{~h}$. The extract was filtered using a filter paper (110 mm; Advantec no. 2), and the filtrate was concentrated at $60^{\circ} \mathrm{C}$ using a rotary evaporator (Buchi Labortechnik AG, Flawil, Switzerland) and then lyophilized by a Bondiro Freeze Dryer (IlShinBio, Dongducheon, Korea) into a dry powder (yield, 17.9\%) $(12,13)$. The dry powder was resuspended in distilled water, and then filtered through a $0.2 \mu \mathrm{m}$ filter. The PMR extract samples were deposited at the College of Pharmacy, Wonkwang University for future use (voucher no. PMR2014).

Ultra performance liquid chromatography (UPLC) analysis. Identification and quantification of the constituents in the PMR extract was performed by a UPLC system that consisted of a 1290 Infinity UPLC system (Agilent Technologies, Inc., Santa Clara, CA, US), with Binary pump and Diode Array Detector (DAD). The chromatographic separation was performed on C18 RP column (Halo C18 RP; $2.7 \mu \mathrm{m} ; 4.6 \times 100 \mathrm{~mm}$ ). Two solvents, solvent $\mathrm{A}$ and $\mathrm{B}$, were used for the mobile phases of UPLC. Solvent A was $10 \mathrm{mM}$ phosphate buffer in $\mathrm{H}_{2} \mathrm{O}$ and solvent B was $100 \%$ acetonitrile. The gradient elution was progressed at a flow rate of $1.0 \mathrm{ml} / \mathrm{min}$ under the program: (A) $/(\mathrm{B})=90 / 10$ for $0 \mathrm{~min}$, followed by $90 / 10$ for $5 \mathrm{~min}$, and 40/60 for $25 \mathrm{~min}$ and hold for $4 \mathrm{~min}$. The UV wavelength of the detector was fixed at $210 \mathrm{~nm}$ and monitored for $25 \mathrm{~min}$. Column temperature was maintained constantly at $40^{\circ} \mathrm{C}$. The PMR extract and standard were dissolved in methanol and filtered using a $0.2 \mu \mathrm{m}$ membrane filter (Millipore; Merck KGaA, Billerica, MA, USA).

Cell culture and osteoclast differentiation. Bone marrow cells (BMCs) were obtained by flushing the femurs and tibiae of 5-week-old ICR mice as described previously (14). To obtain BMMs, BMCs were seeded on culture dishes in $\alpha$-MEM supplemented with $10 \%$ FBS and M-CSF $(10 \mathrm{ng} / \mathrm{ml})$ and cultured for 1 day. Nonadherent cells were transferred 
to $10 \mathrm{~cm}$ petri dishes and further cultured in the presence of M-CSF (30 ng/ml) for 3 days. Floating cells were discarded and adherent cells on dish bottoms were classified as BMMs, which are osteoclast precursors. To induce BMMs differentiation into osteoclasts, BMMs were cultured for 3 days with M-CSF (30 ng/ml) and RANKL (100 ng/ml) in the presence or absence of PMR. Then, cells were fixed with $3.7 \%$ formaldehyde for $10 \mathrm{~min}$, permeabilized with $0.1 \%$ Triton $\mathrm{X}-100$ for $10 \mathrm{~min}$, and stained for $30 \mathrm{~min}$ at $37^{\circ} \mathrm{C}$ with TRAP solution $[1 \mathrm{mg} / \mathrm{ml}$ fast red violet LB, $100 \mu \mathrm{g} / \mathrm{ml}$ naphthol AS-MX phosphate, $0.1 \mathrm{M}$ sodium acetate $(\mathrm{pH} 5.0), 50 \mathrm{mM}$ sodium tartrate]. TRAP-positive cells were counted as osteoclasts and multinuclear osteoclast cells (MNCs; >3 nuclei/cell) under an inverted microscope (Leica Microsystems, Bannockburn, IL, USA). A total of four fields of a single well were selected randomly and three wells were counted for each group. For the total TRAP activity assay, cells were lysed with $1 \%$ Triton X-100 in TRAP assay buffer $(50 \mathrm{mM}$ sodium tartrate and $0.1 \mathrm{M}$ sodium acetate, $\mathrm{pH}$ 5.2) for $10 \mathrm{~min}$ and incubated in a TRAP assay buffer with $1 \mathrm{mg} / \mathrm{ml}$ p-nitrophenyl phosphate. Following $30 \mathrm{~min}$ of incubation at $37^{\circ} \mathrm{C}$, the reaction was stopped with $1 \mathrm{M} \mathrm{NaOH}$, and the absorbance was measured at $405 \mathrm{~nm}$ using a spectrophotometer.

Cytotoxicity assay. The XTT assay was performed to examine the cytotoxic effect of PMR on BMMs. Cells were seeded in a 96-well plate then cultured for 3 days with various concentrations of PMR in the presence of M-CSF (30 ng/ml). Following the incubation period, XTT solution $(50 \mu \mathrm{l})$ was added to each well and incubated for $4 \mathrm{~h}$. Absorbance was measured using an ELISA reader (Thermomax; Molecular Devices, Sunnyvale, CA, USA) at $450 \mathrm{~nm}$.

Actin ring staining. Cell were fixed with $3.7 \%$ formaldehyde for $10 \mathrm{~min}$ and permeabilized with $0.1 \%$ Triton X-100 for $5 \mathrm{~min}$. The cells were blocked with $1 \%$ bovine serum albumin (BSA) and then incubated with Texas red-phalloidin (Molecular probes; Thermo Fisher Scientific, Inc.) at room temperature for $30 \mathrm{~min}$. Following washing with PBS, nuclei were counterstained with $0.1 \mu \mathrm{g} / \mathrm{ml}$ DAPI for $1 \mathrm{~min}$. The images were captured using a fluorescence microscope (EVOS FL; Thermo Fisher Scientific, Inc.).

Reverse transcription-quantitative polymerase chain reaction $(R T-q P C R)$. Total RNA was isolated with Isol-RNA lysis reagent (5 Prime Inc., Gaithersburg, MA, USA), according to the manufacturer's instructions. To obtain cDNA, equal amounts of total RNA were reverse-transcribed using ReverTra Ace qPCR RT kit (Toyobo Co., Ltd., Osaka, Japan). qPCR was performed in a $20 \mu \mathrm{l}$ reaction mixture containing $10 \mu \mathrm{l}$ of SYBR Green Real-Time PCR Master Mix (Toyobo Co., Ltd.), $10 \mathrm{pM}$ of forward primer/reverse primer, and $1 \mathrm{ng}$ of cDNA using StepOnePlus RT-PCR system (Applied Biosystems; Thermo Fisher Scientific, Inc.). The primers used to detect the genes of interest were as follows: c-Fos, forward 5'-CTGGTGCAGCCCACTCTGGTC-3' and reverse 5'-CTTTCAGCAGATTGGCAATCTC-3'; NFATc1, forward 5'-CAACGCCCTGACCACCGATAG-3' and reverse 5'-GGC TGCCTTCCGTCTCATAGT-3'; TRAP, forward 5'-ACTTCC CCAGCCCTTACTAC-3' and reverse 5'-TCAGCACATAGC
CCACACCG-3'; OSCAR, forward 5'-CTGCTGGTAACG GATCAGCTCCCCAGA-3' and reverse 5'-CCAAGGAGC CAGAACCTTCGAAACT-3'; Atp6v0d2, forward 5'-TCA GATCTCTTCAAGGCTGTGCTG-3' and reverse 5'-GTG CCAAATGAGTTCAGAGTGATG-3'; Cathepsin K, forward 5'-ACGGAGGCATTGACTCTGAAGATG-3' and reverse 5'-GTTGTTCTTATTCCGAGCCAAGAG-3'; Runx2, forward 5'-CCCAGCCACCTTTACCTACA-3' and reverse 5'-CAG CGTCAACACCATCATTC-3'; alkaline phosphatase (ALP), forward 5'-CAAGGATATCGACGTGATCATG-3' and reverse 5'-GTCAGTCAGGTTGTTCCGATTC-3'; Osteocalcin, forward 5'-CTCTCTGCTTGAGGAAGAAGCTC-3' and reverse 5'-GTGCCCCTTAGGCACTAGGAG-3'; Osterix, forward 5'-CTCTCTGCTTGAGGAAGAAGCTC-3' and reverse 5'-GTGCCCCTTAGGCACTAGGAG-3'; Osteopontin, forward 5'-TCTGATGAGACCGTCACTGC-3' and reverse 5'-CCTCAGTCCATAAGCCAAGC-3'; and GAPDH, forward 5'-ACCACAGTCCATGCCATCAC-3' and reverse 5'-TCCACC ACCCTGTTGCTGTA-3'. The mouse GAPDH gene was used as the internal control. The thermal cycling conditions were as follows: $95^{\circ} \mathrm{C}$ for $15 \mathrm{~min}$, followed by 40 cycles of $95^{\circ} \mathrm{C}$ for $15 \mathrm{sec}, 58^{\circ} \mathrm{C}$ for $15 \mathrm{sec}$, and $72^{\circ} \mathrm{C}$ for $15 \mathrm{sec}$. The specificity of the SYBR green assays was confirmed by melting-point analysis. Expression data were calculated from the cycle threshold (Cq) value using the $2^{-\Delta \Delta \mathrm{Cq}}$ method (15).

Western blot analysis. Whole-cells were lysed in a buffer containing $50 \mathrm{mM}$ Tris- $\mathrm{HCl}, 150 \mathrm{mM} \mathrm{NaCl}, 5 \mathrm{mM}$ EDTA, $1 \%$ Triton $\mathrm{X}-100,1 \mathrm{mM}$ sodium fluoride, $1 \mathrm{mM}$ sodium vanadate, $1 \%$ deoxycholate, and protease inhibitors. The lysates were centrifuged at $16,128 \mathrm{x} \mathrm{g}$ for $20 \mathrm{~min}$ and the supernatants were collected. The protein concentration was measured using a BCA protein assay kit (Thermo Fisher Scientific Inc.). Equal amounts of protein $(30 \mu \mathrm{g})$ were separated on $10 \%$ SDS-polyacrylamide gels and were transferred by electro-blotting onto polyvinylidene difluoride membrane (Bio-Rad Laboratories, Inc., Hercules, CA, USA). Membranes were incubated with blocking buffer consisting of 5\% nonfat dry milk in $10 \mathrm{mM}$ Tris- $\mathrm{HCl} \mathrm{pH} 7.5 / 150 \mathrm{mM} \mathrm{NaCl} / 0.1 \%$ Tween-20 (TBST) for $1 \mathrm{~h}$ at room temperature, then probed with the indicated primary antibodies overnight at $4^{\circ} \mathrm{C}$. The membraned were then washed with TBST three times $(10 \mathrm{~min}$ for each wash), and after washing, they were incubated with horseradish peroxidase-conjugated secondary antibodies [1:5,000 dilution; goat anti-mouse immunoglobulin G (IgG)-horseradish peroxidase (HRP), cat. no. SC-2005; goat anti-rabbit IgG-HRP, cat. no. SC-2004; rabbit anti-goat IgG-HRP, cat. no. SC-2768] for $1 \mathrm{~h}$ at room temperature and washed with TBST three times. Chemiluminescent signals were detected using the FlourChemE system (version 1.4.1; ProteinSimple, San Jose, CA, USA) with western enhanced chemiluminescence substrate (Bio-Rad Laboratories, Inc.).

Transfection and luciferase reporter assay. 293T cells were seeded in a 96 -well plate at a density of $2 \times 10^{4}$ cells/well and incubated for $24 \mathrm{~h}$ before transfection. The cells were transiently cotransfected with TRAF6 and NF- $\kappa$ B luciferase reporter vector (pGL3-Basic Vector; Promega Corporation, Madison, WI, USA) using the X-tremeGENE9 DNA transfection reagent (Roche Diagnostics $\mathrm{GmbH}$ ) for $3 \mathrm{~h}$ in serum-free 
DMEM and then the medium were replaced by DMEM complete medium. After $12 \mathrm{~h}$ of transfection, the transfected cells were incubated with or without PMR. The cells were lysed with lysis buffer, and luciferase activity was measured using a luciferase assay system (Promega Corporation). Luciferase activity were normalized to the $\beta$-galactosidase activity in each sample.

Culture of primary mouse osteoblasts and assays. Calvaria was isolated from 1-day-old neonatal ICR mice and was digested with $0.1 \%$ collagenase (Sigma-Aldrich; Merck KGaA) and $0.2 \%$ dispase (Roche Diagnostics $\mathrm{GmbH}$ ) for $5 \mathrm{~min}$ at $37^{\circ} \mathrm{C}$ (16). After removal of the medium, the remaining tissue was digested 4 times for $10 \mathrm{~min}$ at $37^{\circ} \mathrm{C}$. Cell fractions were collected and used as primary mouse osteoblasts. Cells were cultured for 3 days, and adherent cells were used as osteoblasts. Primary mouse osteoblasts were seeded at a density of $1.5 \times 10^{4}$ cells/well into 48 -well plates. To induce the osteoblast differentiation, cells were induced by osteogenic inducers: $50 \mu \mathrm{g} / \mathrm{ml} \mathrm{AA}$ and $10 \mathrm{mM} \beta$-GP. After $24 \mathrm{~h}$, cells were cultured in the presence of $10 \mathrm{mM} \beta$-GP and $50 \mu \mathrm{g} / \mathrm{ml} \mathrm{AA}$ with or without PMR to induce osteoblast differentiation. On day 3, the medium was replaced with fresh medium containing $\beta$-GP and AA with or without PMR. For ALP staining, AA $/ \beta$-GP induced osteoblasts were washed twice with PBS and fixed in $3.7 \%$ formaldehyde. Then, they were stained with a mixture of $0.1 \mathrm{mg} / \mathrm{ml}$ naphthol AS-MX phosphate, $0.6 \mathrm{mg} / \mathrm{ml}$ fast-blue BB salt, $2 \mathrm{mM} \mathrm{MgCl}_{2}, 5 \mathrm{ml} \mathrm{N}, \mathrm{N}$-dimethylformamide (MP Biomedicals, Illkirch, France), and $100 \mathrm{mM}$ Tris-HCl (pH 8.8) buffer at $37^{\circ} \mathrm{C}$ for 5 to $10 \mathrm{~min}$. When the cells turned blue, they were washed twice with PBS. For alizarin red $\mathrm{S}$ (ARS; Sigma-Aldrich; Merck KGaA) staining, cells were fixed in $3.7 \%$ formaldehyde in sterile PBS and stained with $2 \%$ ARS solution.

Bone loss model. To study the effect of PMR on LPS-induced bone loss in vivo, ICR (5-week-old males) mice were randomly divided into 4 experimental groups $(\mathrm{n}=5 \mathrm{mice} / \mathrm{group}$; 23-28 g body weight): Control group, LPS-injected (disease) group, and LPS-injected and PMR-treated group (200 and $400 \mathrm{mg} / \mathrm{kg} /$ day). After acclimatization for 1 week, control mice were orally administered phosphate-buffered saline (PBS), LPS-injected mice were injected with LPS, and PMR-treated mice were orally administered with PMR. PBS and PMR were orally administered every day for 10 days to the treated and the control groups, respectively. LPS $(5 \mathrm{mg} / \mathrm{kg})$ and PBS were injected intraperitoneally on days 1,4 , and 7 to the disease and the control groups, respectively. Mice were euthanized on day $10(17,18)$, the left femurs were analyzed by high-resolution micro-computed tomography ( $\mu \mathrm{CT}$; Skyscan 1172), and the right femurs were fixed in $4 \%$ paraformaldehyde in PBS for 1 day, decalcified for 3 weeks in 12\% EDTA, and then embedded in paraffin. Sections (5 $\mu \mathrm{m}$ thick) were prepared using a Leica microtome RM2125RTM (Leica Microsystems, Inc., Bannockburn, IL, USA). The sections were stained with hematoxylin-eosin (H\&E) for histological examination, and other sections were stained with TRAP to reveal osteoclasts on the bone surface. The parameters for bone resorption, including the number of osteoclasts per two fields of view per slide ( $\mathrm{n}=3$ slides per group) were quantified using ImageJ $1.50 \mathrm{i}$ software (National Institutes of Health, Bethesda, MD, USA). Serum mouse C-teminal telopeptide of type I collagen (CTX-1) levels, a specific marker of bone resorption, were measured using a CTX-1 ELISA kit (cat. no. MBS726456; MyBioSource Inc., San Diego, CA, USA).

Micro-computed tomography analysis. $\mu \mathrm{CT}$ images were scanned with a high-resolution SkyScan 1172 system (SkyScan/Bruker, Kontich, Belgium) with the X-ray source at $50 \mathrm{kV}$ and $201 \mu \mathrm{A}$ with a $0.5-\mathrm{mm}$ aluminum filter. Images were captured every $0.7^{\circ}$ over an angular range of $180^{\circ}$. Raw images were reconstructed from a stack of 2-dimensional images using commercial software (NRecon, version 1.6.2.0; SkyScan). The trabecular bones between 6.889 and $3.608 \mathrm{~mm}$ away from the epiphyseal plate of distal femurs were manually selected as a region of interest (ROI) and the contouring of images was performed every 50 axial slices. The bone morphometric parameters of ROI calculated using proprietary software (CTAn; Skyscan): Trabecular bone volume as a fraction of total tissue volume (BV/TV, \%), trabecular thickness (Tb.Th, $\mu \mathrm{m}$ ), trabecular seperation (Tb.Sp, $\mu \mathrm{m}$ ) and trabecular number (Tb.N, 1/mm). The three-dimensional visualization images were obtained by using the 3D-creator software (Ant; SkyScan).

Statistical analysis. Experiments were conducted independently at least three times and all data were presented as mean \pm standard deviation. All statistical analyses were performed with SPSS version 12.0 Software (SPSS, Inc., Chicago, IL, USA). Statistical differences were analyzed using one-way analysis of variance with Fisher's Least Significant Difference test. $\mathrm{P}<0.05$ was considered to indicate a statistically significant difference.

\section{Results}

PMR inhibits RANKL-induced osteoclast differentiation. To identify the main constituents of PMR, UPLC analysis was performed. By comparing with emodin and 2,3,5,4'-tetrahydroxystilbene 2-O- $\beta$-D-glucoside (THS), the two standard marker compounds, emodin and THS were identified in the extract of PMR (Fig. 2). Treatment of BMMs with M-CSF and RANKL for 4 days induced TRAP-positive multinucleated osteoclasts (Fig. 3A). As shown in Fig. 3A, PMR treatment reduced the number of TRAP-positive cells and inhibited RANKL-induced TRAP activity in a dose-dependent manner. In addition, PMR treatment $(25,50$ and $100 \mu \mathrm{g} / \mathrm{ml})$ suppressed the formation of TRAP-positive MNCs (Fig. 3A), without affecting the viability of osteoclast precursor cells (Fig. 3C), suggesting that the inhibitory effect of PMR on osteoclast differentiation is not due to cytotoxicity. Based on the results of morphological analysis and MNC formation, the dose of $50 \mu \mathrm{g} / \mathrm{ml}$ PMR was used for subsequent experiments to investigate its antiosteoclastogenic effect. The formation of F-actin rings is necessary for osteoclastic bone resorption, therefore the effect of PMR on F-actin ring formation was examined next. Characteristic F-actin ring formation was observed in the untreated control, whereas treatment with PMR strongly inhibited the F-actin ring formation and morphology (Fig. 3B). These findings suggested that PMR distinctly inhibited 

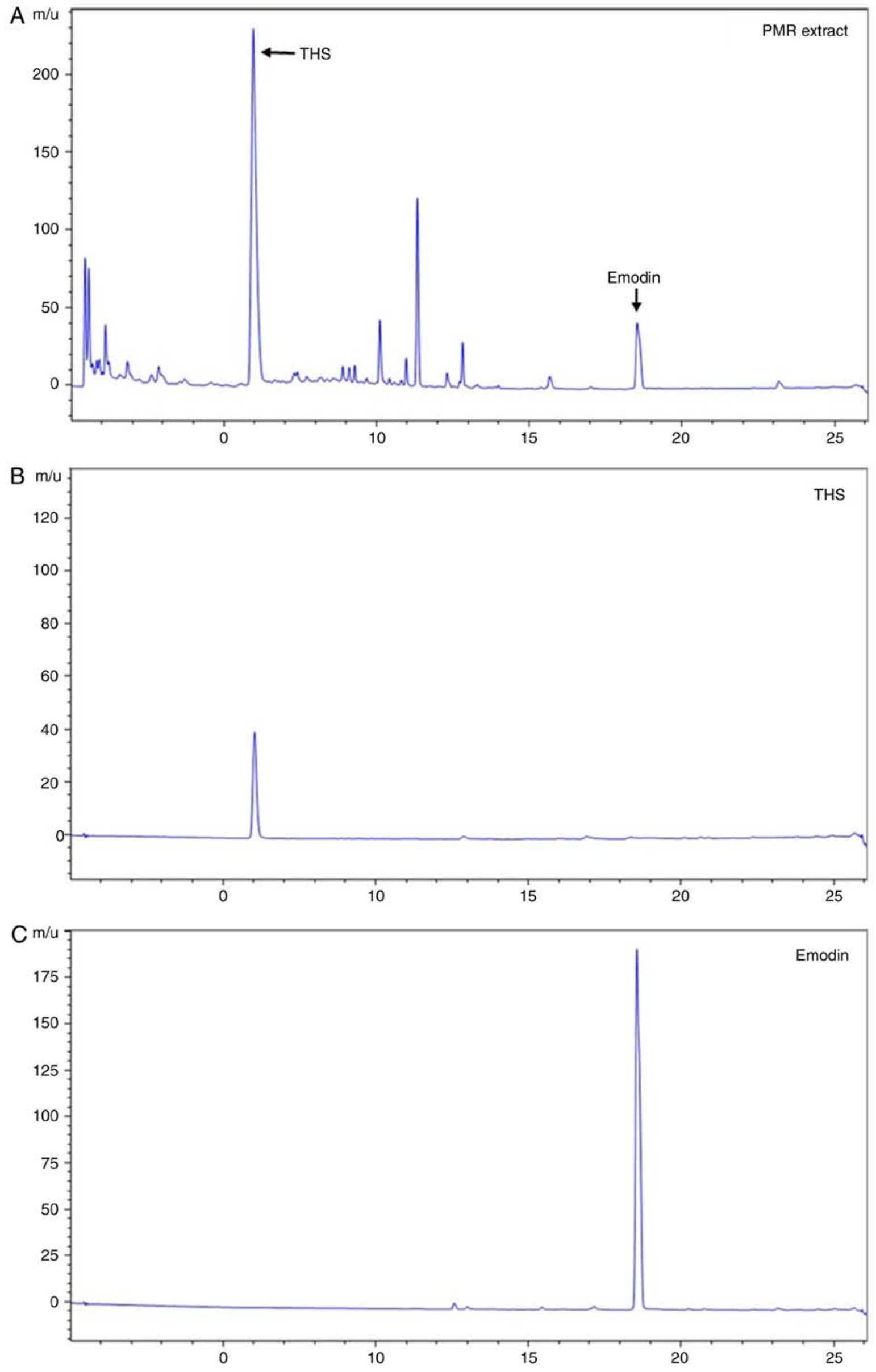

Figure 2. Ultra-performance liquid chromatography chromatograms of PMR and standard compounds. (A) PMR.(B) THS. (C) Emodin. PMR, Polygoni Multiflori Radix; THS, 2,3,5,4'-tetrahydroxystilbene 2-O- $\beta$-D-glucoside. 
A
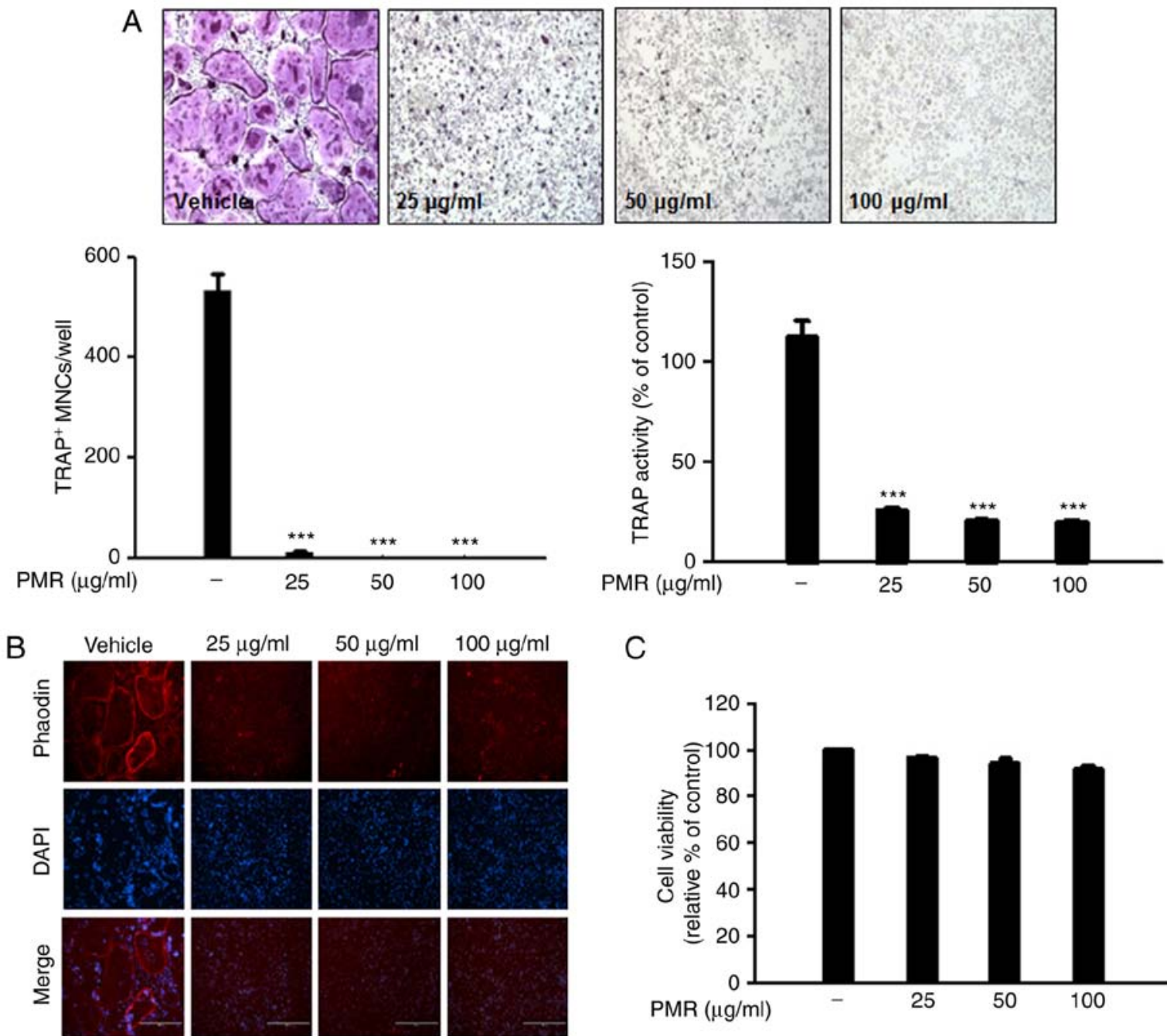

C

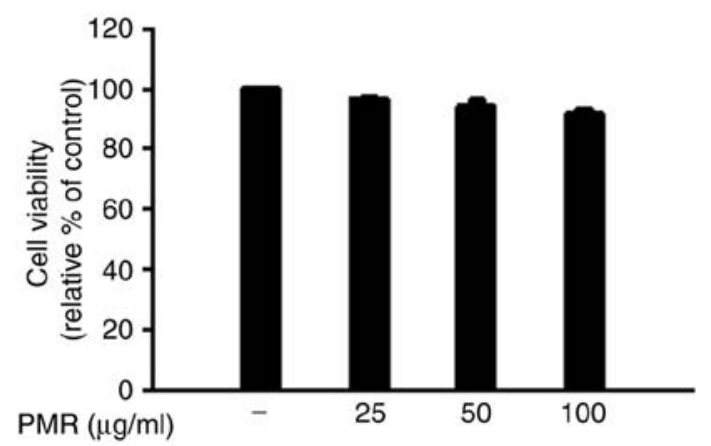

Figure 3. Effects of PMR on RANKL-induced osteoclast differentiation in BMMs. BMMs were cultured with vehicle or PMR (25, 50 and $100 \mu \mathrm{g} / \mathrm{ml})$ in the presence of M-CSF (30 ng/ml) and RANKL $(100 \mathrm{ng} / \mathrm{ml})$ for 4 days. (A) Cultured cells were fixed and stained for TRAP. TRAP activity was determined by measuring optical density values at $450 \mathrm{~nm}$. TRAP-positive cells containing three or more nuclei were counted as MNCs. (B) Cellular morphology of F-actin rings were observed by immunofluorescence. F-actin rings were stained by Texas-red phalloidin (red signal) and nuclei were stained by DAPI (blues signal). (C) Cell viability of BMMs in the presence of PMR and M-CSF (30 ng/ml) was determined using the XTT assay. ${ }^{* * *}$ P $<0.001$ vs. control group. PMR, Polygoni Multiflori Radix; RANKL, receptor activator of nuclear factor-kB ligand; BMMs, bone marrow macrophages; M-CSF, macrophage colony stimulating factor; TRAP, tartrate-acid resistant acid phosphatase; MNCs, multinuclear osteoclast cells.

TRAP-positive multinucleated osteoclasts and F-actin ring formation.

PMR inhibits RANKL-mediated induction of $c-F o s$ and NFATcl. Since PMR inhibited RANKL-induced osteoclast differentiation, the effect of PMR on the expression of c-Fos and NFATc1, transcription factors essential for osteoclast differentiation, was investigated. RT-qPCR analysis indicated that PMR treatment significantly inhibited the transcriptional levels of c-Fos and NFATc1 at 6, 12 and $48 \mathrm{~h}$ (Fig. 4A and B). In addition, RANKL-induced expression of c-Fos and NFATc1 mRNA was suppressed by PMR in a dose-dependent manner (Fig. 4A and B). Western blot analysis confirmed that PMR treatment significantly decreased RANKL-induced expression levels of c-Fos and NFATcl at the protein level (Fig. 4C). These results suggested that PMR inhibited RANKL-induced osteoclast differentiation through downregulation of c-Fos and NFATcl.
PMR inhibits RANKL-induced $m R N A$ expression of TRAP, OSCAR, ATP6vOd2 and Cathepsin K. NFATc1 induces the expression of various osteoclast-specific genes, including TRAP, OSCAR, ATP6v0d2 and Cathepsin K, during RANKL-induced osteoclast differentiation (8). To characterize the PMR-inhibitory effect on osteoclast differentiation through regulation of osteoclast-specific gene expression, the mRNA levels of genes associated with osteoclast differentiation were analyzed using RT-qPCR. PMR treatment downregulated the expression of TRAP and OSCAR (Fig. 5A), which are associated with osteoclast differentiation, as well as suppressed the expression of ATPv0d2 (Fig. 5A), which affects cell-to-cell fusion and cell migration. The expression of Cathepsin $\mathrm{K}$, which is related to bone-resorbing activity, was also inhibited by PMR treatment at $48 \mathrm{~h}$ (Fig. 5A). Furthermore, PMR treatment significantly reduced the mRNA expression of TRAP, OSCAR, Atp6v0d2 and Cathepsin $\mathrm{K}$ in a dose-dependent manner (Fig. 5B). Based on these observations, PMR may have 

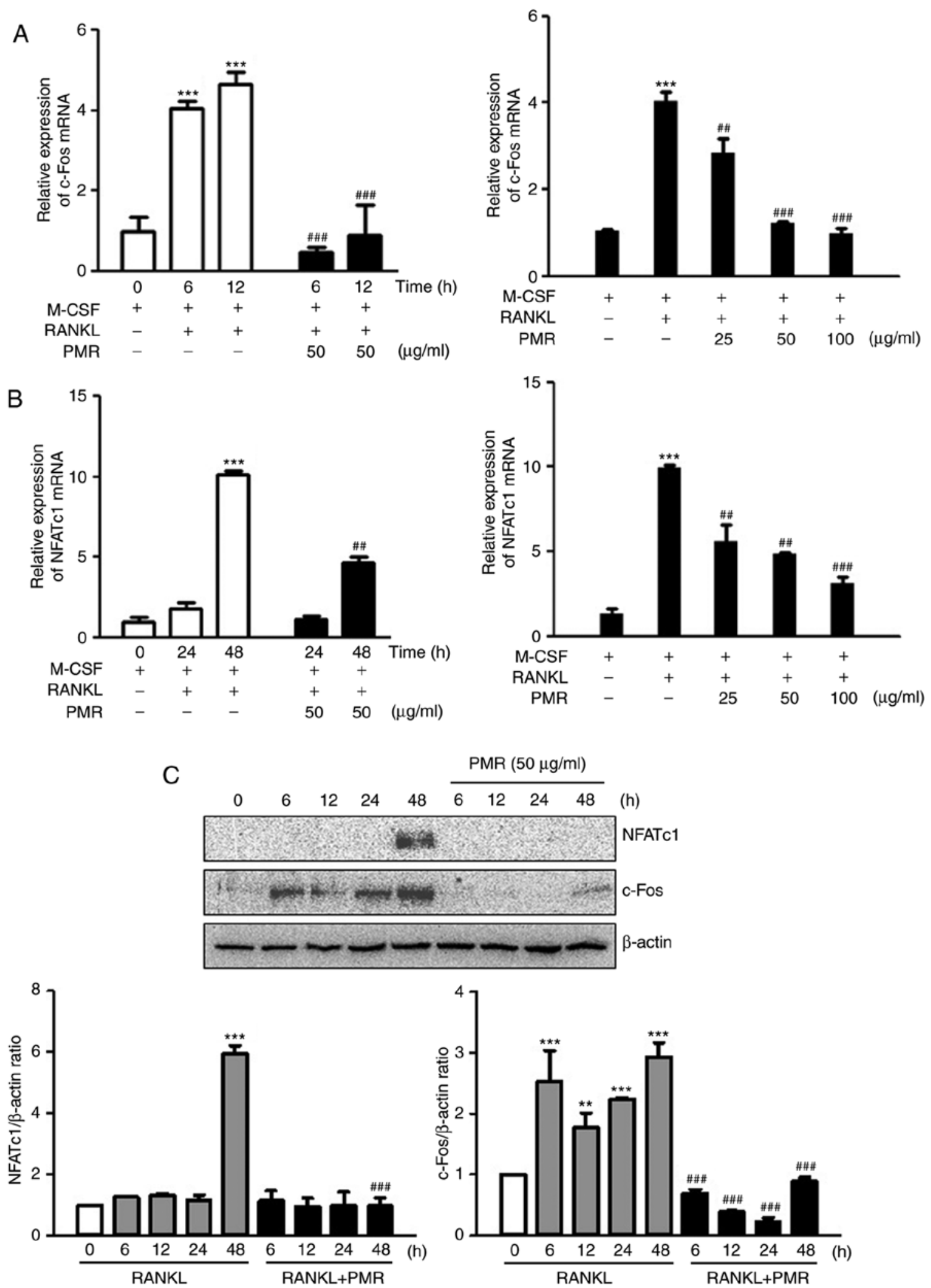

Figure 4. Effects of PMR on the RANKL-induced expression of c-Fos and NFATc1 in BMMs. BMMs were treated with PMR and then stimulated with M-CSF (30 ng/ml) and RANKL (100 ng/ml) at the indicated time periods and concentrations. (A) The mRNA expression levels of c-Fos and (B) NFATc1 were analyzed by reverse transcription-quantitative polymerase chain reaction. (C) Western blot analysis was performed to confirm the results at the protein level. $\beta$-actin was used as an internal control. ${ }^{* *} \mathrm{P}<0.01$ and ${ }^{* * *} \mathrm{P}<0.001$ vs. control group; ${ }^{\# \#} \mathrm{P}<0.01$ and ${ }^{\# \# \#} \mathrm{P}<0.001$ vs. RANKL-treated group at the corresponding time and concentration. PMR, Polygoni Multiflori Radix; RANKL, receptor activator of nuclear factor-kB ligand; c-Fos, Fos proto-oncogene; NFATc1, nuclear factor of activated T-cell; BMMs, bone marrow macrophages; M-CSF, macrophage colony stimulating factor.

inhibited osteoclast differentiation by controlling the expression of several genes that are necessary for this process.
PMR suppresses the RANKL-induced $p 38$ and $E R K / N F-\kappa B$ signaling pathways. A key signaling event induced by the 
A
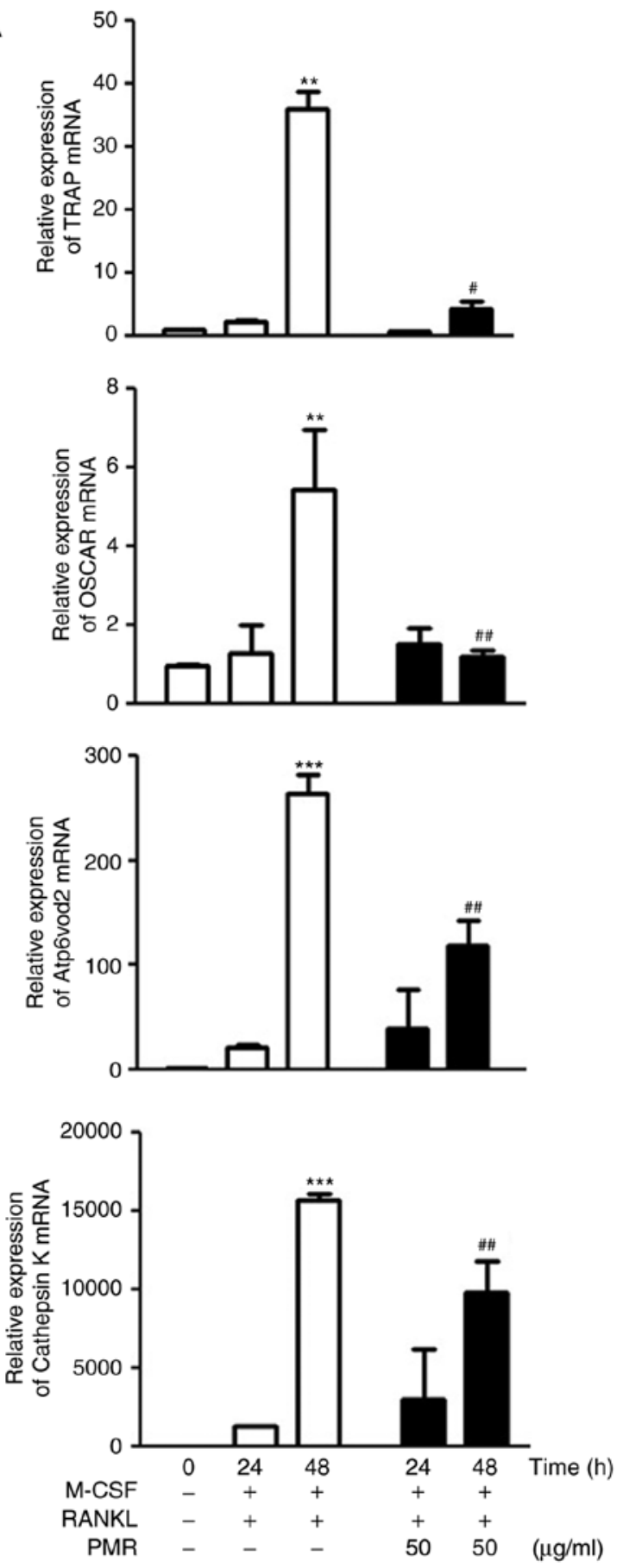

B
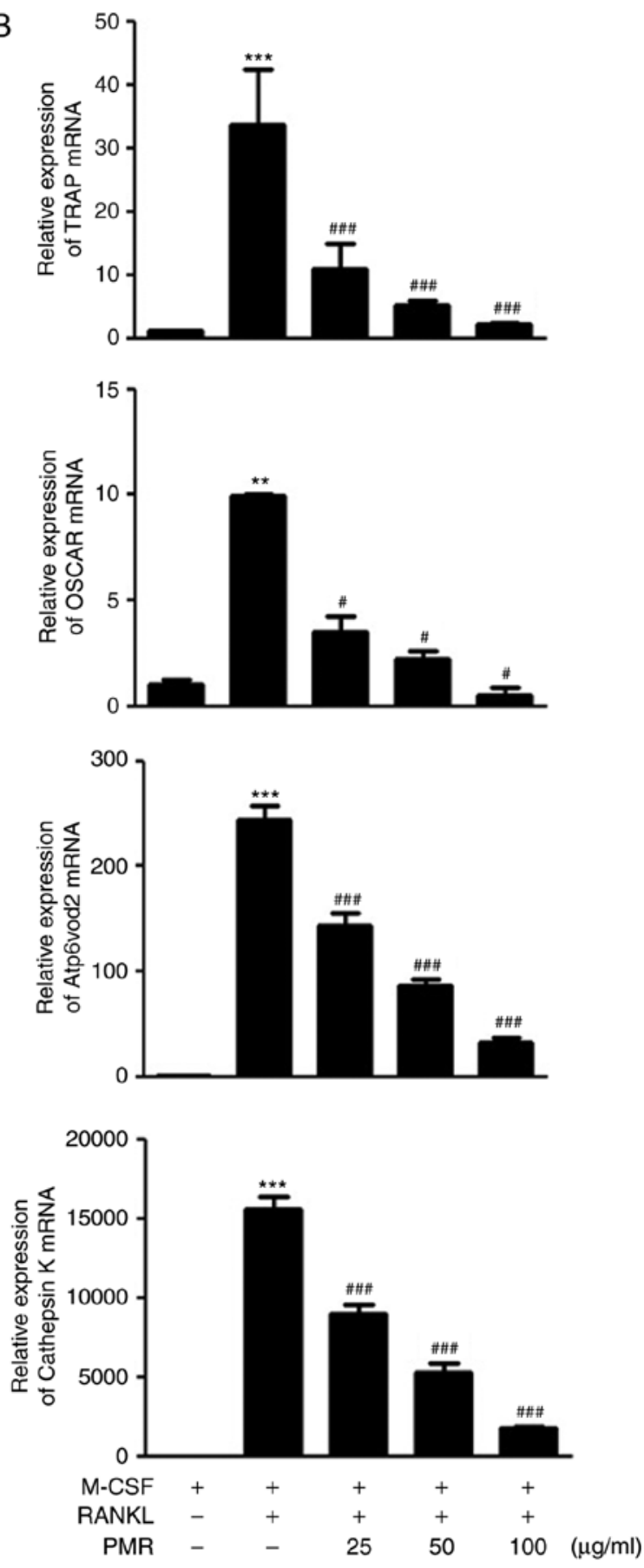

Figure 5. (A and B) PMR inhibits the expression of osteoclast-specific genes. BMMs were stimulated with M-CSF ( $30 \mathrm{ng} / \mathrm{ml}) \mathrm{and}$ RANKL (100 ng/ml) in the presence or absence of PMR for the indicated time periods and indicated concentrations. The mRNA expression levels of TRAP, OSCAR, ATP6vod2 and Cathepsin $\mathrm{K}$ were analyzed by reverse transcription-quantitative polymerase chain reaction. ${ }^{* *} \mathrm{P}<0.01$ and ${ }^{* * * *} \mathrm{P}<0.001$ vs. control group; ${ }^{\sharp} \mathrm{P}<0.05,{ }^{\# \#} \mathrm{P}<0.01$ and

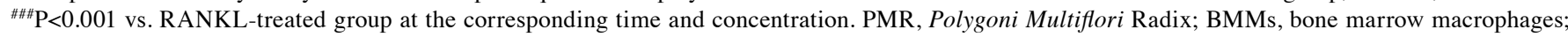
M-CSF, macrophage colony stimulating factor; RANKL, receptor activator of nuclear factor-kB ligand; TRAP, tartrate-acid resistant acid phosphatase; OSCAR, osteoclast-associated receptor; ATP6vod2, ATPase $\mathrm{H}^{+}$transporting lysosomal $38 \mathrm{kDa}$ V0 subunit d2.

binding of RANKL to it receptor, RANK, is the activation of mitogen-activated protein kinase (MAPKs), Akt and NF- $\mathrm{KB}$ signaling (6). To identify the molecular mechanism of inhibition and the pathways influenced by PMR, BMMs were treated with RANKL in the absence or presence of PMR for 0-30 min. RANKL-induced activation of p38 and ERK was inhibited by PMR treatment within 5 min, whereas phosphorylation of JNK was not affected by treatment with PMR (Fig. 6A). These findings suggest that the inhibitory effect of PMR on osteoclast differentiation is primarily mediated by the suppression of the p38 and ERK signaling pathways. NF-kB is downstream of MAPK signaling and is a major transcription factor for RANKL-activated osteoclastogenesis (19). Thus, degradation of I $\kappa \mathrm{B}$ and activation of NF- $\kappa \mathrm{B}$ were evaluated by western blot analysis. RANKL-induced degradation of IKB and activation of NF- $\kappa B$ were inhibited by PMR treatment within 
A
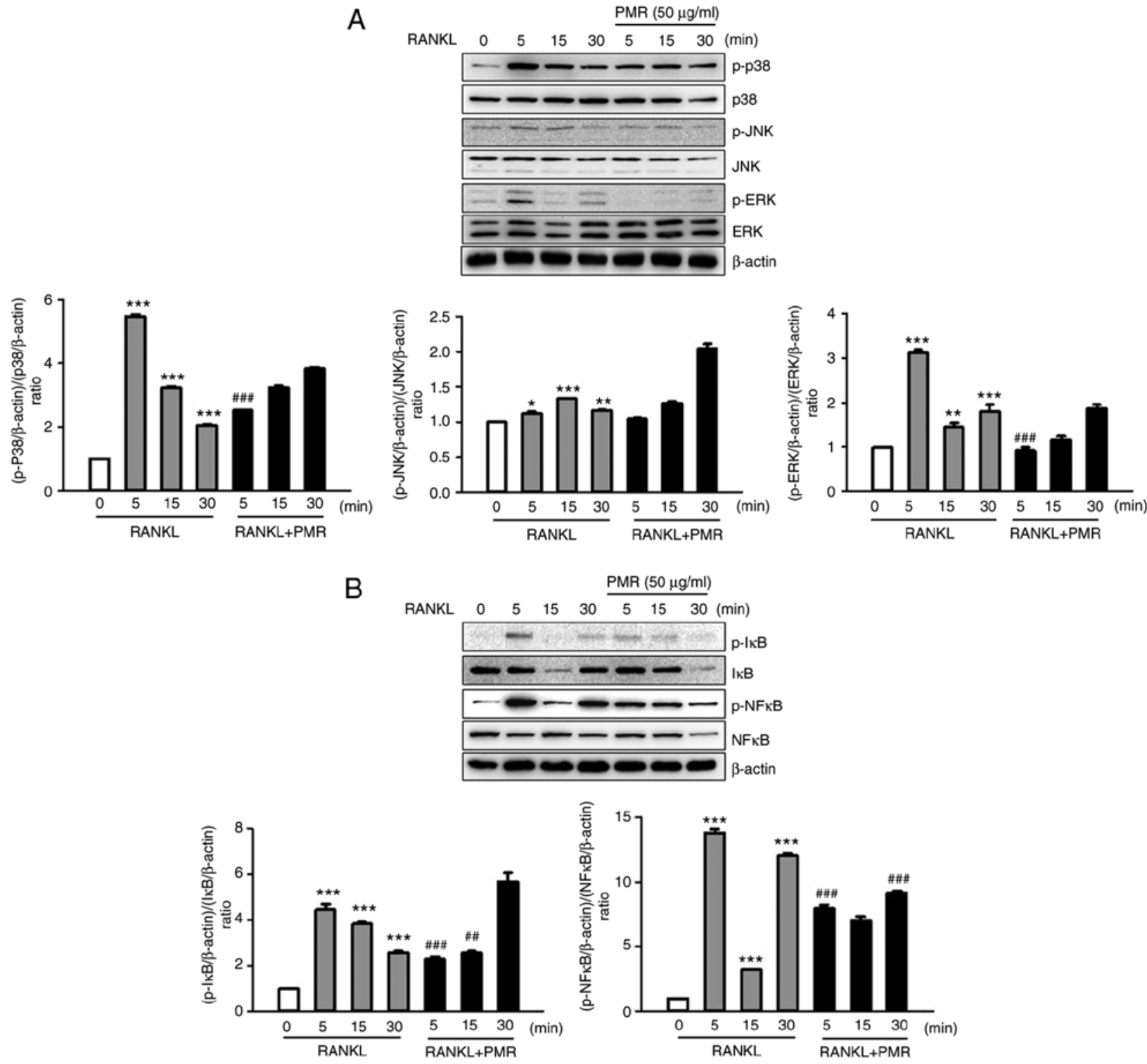

$\underline{\operatorname{PMR}(50 \mu \mathrm{g} / \mathrm{ml})}$
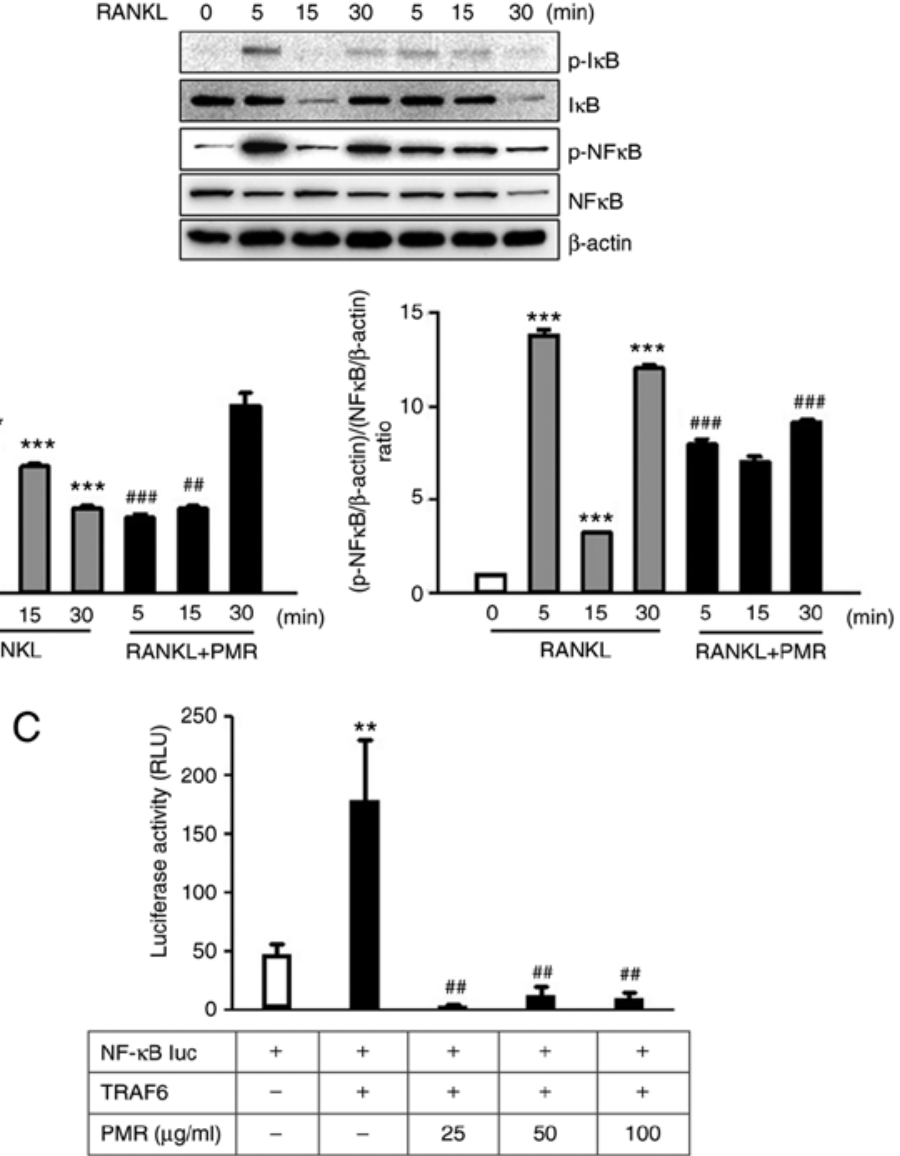

Figure 6. PMR inhibits the RANKL-mediated early signaling in osteoclast differentiation. (A and B) BMMs were incubated without serum for $2 \mathrm{~h}$ and pretreated with PMR $(50 \mu \mathrm{g} / \mathrm{ml})$ for $1 \mathrm{~h}$. RANKL $(100 \mathrm{ng} / \mathrm{ml})$ was added for the indicated time. The cell lysates were analyzed by western blotting with the indicated antibodies. $\beta$-actin was used as an internal control. (C) 293T cells were co-transfected with TRAF6 and NF-kB-luciferase reporter plasmid. Following transfection, the cells were treated with PMR $(25,50$ and $100 \mu \mathrm{g} / \mathrm{ml})$ or vehicle for $24 \mathrm{~h}$. The cells were lysed and used for the luciferase activity. ${ }^{*} \mathrm{P}<0.05,{ }^{* *} \mathrm{P}<0.01$ and ${ }^{* * * *} \mathrm{P}<0.001$ vs. control group; ${ }^{\# \#} \mathrm{P}<0.01$ and ${ }^{\# \# \#} \mathrm{P}<0.001$ vs. RANKL-treated group at the corresponding time and concentration. PMR, Polygoni Multiflori Radix; RANKL, receptor activator of nuclear factor-kB ligand; BMMs, bone marrow macrophages; TRAF6, TNF receptor-associated

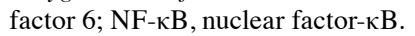

5 min (Fig. 6B). Furthermore, a luciferase reporter assay was performed to examine the effect of PMR on RANKL-induced
NF- $\kappa B$ activation. PMR treatment significantly suppressed the NF- $\mathrm{kB}$ transcription activity (Fig. 6C). These results showed 
A
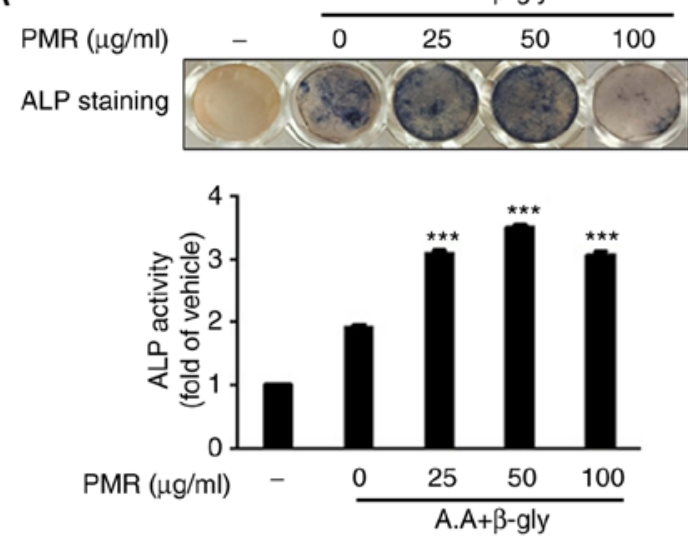

B
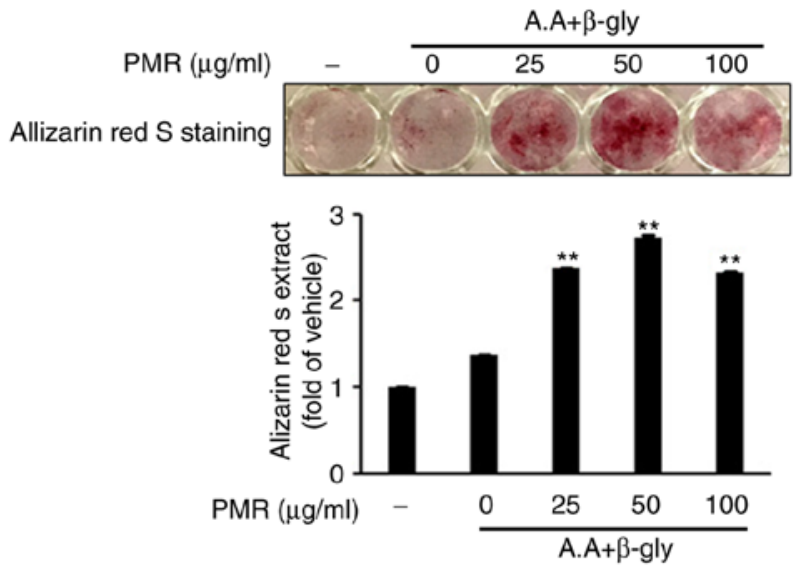

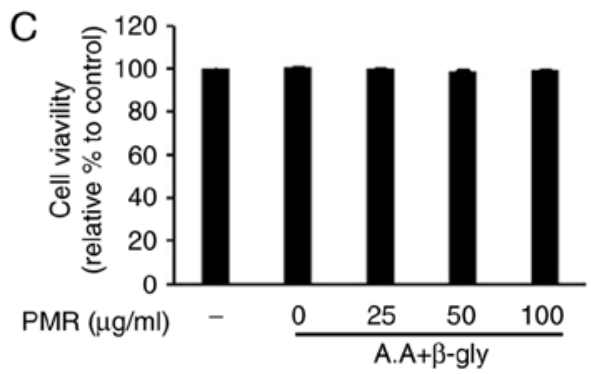

Figure 7. Effects of PMR on the AA/ $\beta$-GP-induced osteoblast differentiation in primary mouse osteoblasts. Primary mouse osteoblasts were seeded in 48-well plates at a density $1.5 \times 10^{4}$ cells/well and cultured in the absence or presence of $\beta$-GP $(10 \mathrm{mM})$ and AA (50 $\left.\mu \mathrm{g} / \mathrm{ml}\right)$. (A) Primary osteoblasts were treated with PMR for 7 days. ALP positive cells were detected by ALP staining (upper panel). ALP activity is expressed as amount of p-nitrophenol released (lower panel). (B) Bone nodule mineralization of primary osteoblasts determined by alizarin red S staining after 21 days (upper panel). The intensity of staining was quantified with cetylpyridium chloride solution (lower panel). (C) Cell viability was determined by the $\mathrm{XTT}$ assay. ${ }^{*} \mathrm{P}<0.05,{ }^{* *} \mathrm{P}<0.01$ and ${ }^{* * * *} \mathrm{P}<0.001$ vs. control. $\mathrm{PMR}$, Polygoni Multiflori Radix; AA, ascorbic acid; $\beta$-GP, $\beta$-glycerophosphate; ALP, alkaline phosphatase.

PMR inhibits RANKL-induced NF- $\kappa B$ transcriptional activity through increased phosphorylation of IкB.

PMR stimulates AA/ $\beta$-GP-induced osteoblast differentiation and $m R N A$ expression of osteoblast differentiation markers. The effect of PMR on osteoblast differentiation was assessed by measuring the ALP activity and staining in the cells, as an early marker of osteoblastogenesis. As illustrated in Fig. 7A, expression and activity of ALP were significantly increased following 25 and $50 \mu \mathrm{g} / \mathrm{ml}$ PMR treatment. These results demonstrated that PMR enhanced osteoblast differentiation by increasing ALP activity. To elucidate the effect of PMR-induced mineralization of extracellular matrix (ECM) during osteoblastogenesis, osteoblasts were stained with ARS 21 days following induction of differentiation. The ECM of the differentiated osteoblasts that were not treated with PMR exhibited only slight mineralization (Fig. 7B). However, increased ECM mineralization was observed in the cells treated with 25 and $50 \mu \mathrm{g} / \mathrm{ml}$ PMR for 21 days (Fig. 7B). The quantified optical density of Alizarin red dissolved in cetylpyridinum chloride solution was significantly higher in the PMR-treated osteoblasts compared with the untreated osteoblasts (Fig. 7B). Of note, PMR treatment had no effect in cell viability of the differentiated osteoblasts (Fig. 7C).

The mRNA expression of genes related to osteoblast differentiation was investigated next by RT-qPCR. The mRNA expression levels of Runx2, ALP, osteocalcin and osterix were demonstrated to be significantly upregulated in the PMR-treated group compared with the untreated osteo- blasts (Fig. 8A). These findings suggested that PMR treatment enhanced osteoblast differentiation and mRNA expression of osteoblast differentiation markers.

PMR promotes AA/ $\beta$-GP-induced osteoblast differentiation via the p38 and Smad pathway. Since the expression of osteoblast-related genes, including Runx2, ALP, osteocalcin and osterix, is modulated via the p38 and Smad signaling pathway, western blot analysis was performed to determine the signaling pathway involved in the PMR-regulated osteoblast differentiation. PMR increased the phosphorylation of p38 after 5 min of treatment and activated ERK and Smad 1/5/8 after 15 min of treatment (Fig. 8B). These results indicate that PMR might upregulate osteoblast-related genes via the p38 and Smad signaling pathways.

PMR prevented LPS-induced bone loss in a mouse model. The efficacy of PMR in inhibiting in vivo bone destruction was investigated in a mouse model of LPS-induced osteolysis. PMR was administered orally to ICR mice for 10 days. In the $\mu \mathrm{CT}$ analyses, a 2- or 3-dimensional visualization of the femoral area revealed a loss in trabecular bone density following LPS treatment (Fig. 9A). LPS-induced bone loss clearly decreased in the femurs of the PMR-treated and LPS-injected group (Fig. 9A). Morphometric analyses of the femurs revealed significant reductions in the BV/TV and an increase in the Tb.Sp. in the LPS-injected group (Fig. 9B). The Tb.N of the LPS-injected group exhibited a slight reduction, even though usually Tb.N expresses significant 

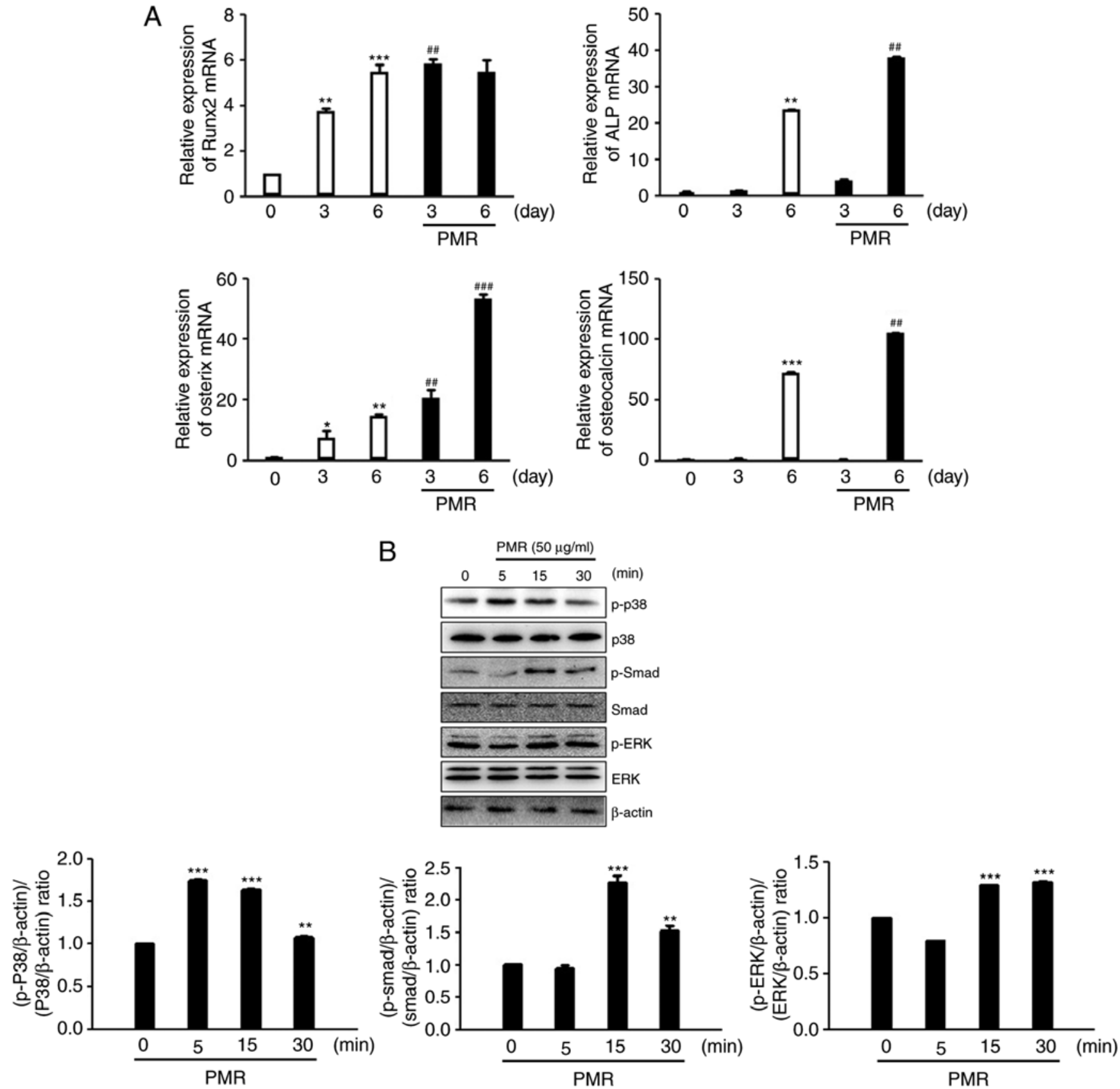

Figure 8. Effect of PMR on osteoblast-specific markers and on the p38 and Smad pathways. (A) Primary mouse osteoblasts were seeded in 6-well plates at a density $2 \times 10^{5}$ cells/well and cultured in the absence or presence of $\beta$-GP $(10 \mathrm{mM})$ and AA $(50 \mu \mathrm{g} / \mathrm{ml})$ for the indicated days. Levels of mRNA expression of Runx2, ALP, osterix and osteocalcin were analyzed by reverse transcription-quantitative polymerase chain reaction. (B) Primary mouse osteoblasts were serum-starved for $2 \mathrm{~h}$, and treated with PMR $(50 \mu \mathrm{g} / \mathrm{ml})$ for the indicated time. The cell lysates were analyzed by western blotting with the indicated antibodies.

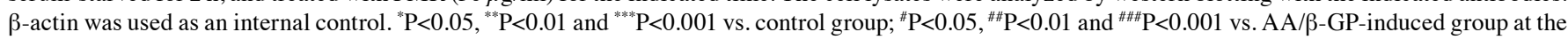
corresponding time. PMR, Polygoni Multiflori Radix; AA, ascorbic acid; $\beta$-GP, $\beta$-glycerophosphate; Runx2, runt-related transcription factor 2; ALP, alkaline phosphatase; p-, phosphorylated; ERK, extracellular signal-regulated kinase.

decrease (Fig. 9B). However, these reductions were recovered in the PMR-treated and LPS-injected group (Fig. 9B). Histological analysis of sections from the femurs also demonstrated the preventive effect of PMR on trabecular bone loss induced by LPS (Fig. 9C). In addition, the increased number of TRAP-positive osteoclasts induced by LPS was significantly reduced in the PMR-treated and LPS-injected group (Fig. 9C). CTX-1 is a new marker of bone resorption, which can be used to assess the antiresorptive activity and to evaluate increases in osteoclast numbers (20). Serum levels of CTX-1 in mice receiving PMR were lower compared with the PMR-untreated and LPS-injected group (Fig. 9D). These findings demonstrated that PMR treatment prevented LPS-induced bone loss in mice by inhibiting bone resorption and stimulating bone formation.

\section{Discussion}

Osteoporosis is a common disease characterized by low bone mass and microarchitectural deterioration of bone tissue, which result in fragility fractures (21). It is widely recog- 
A

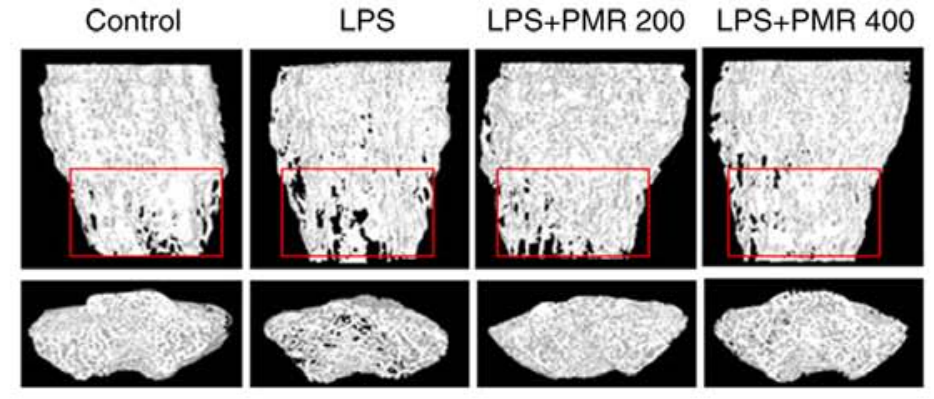

B
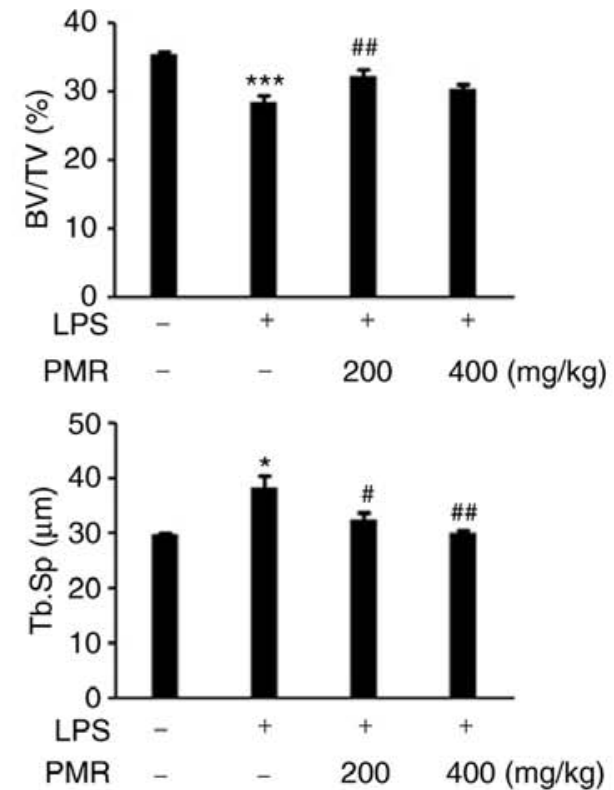
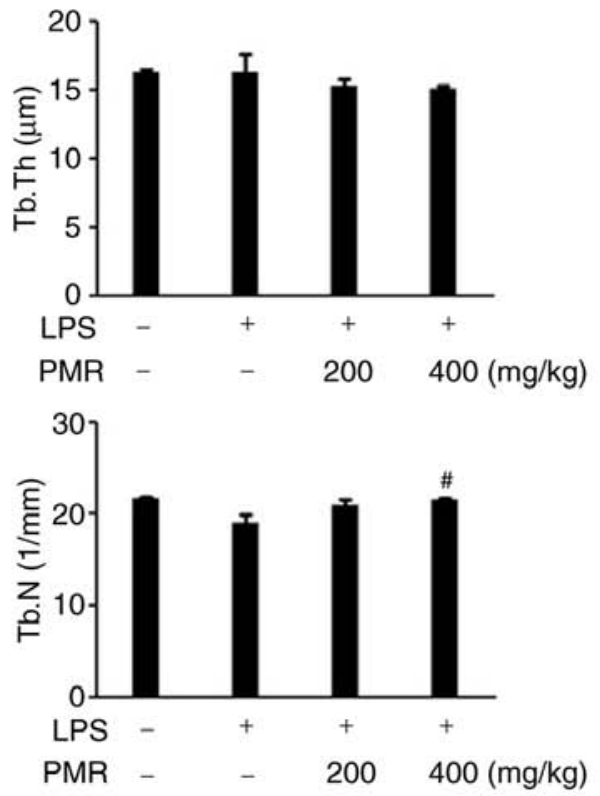

C
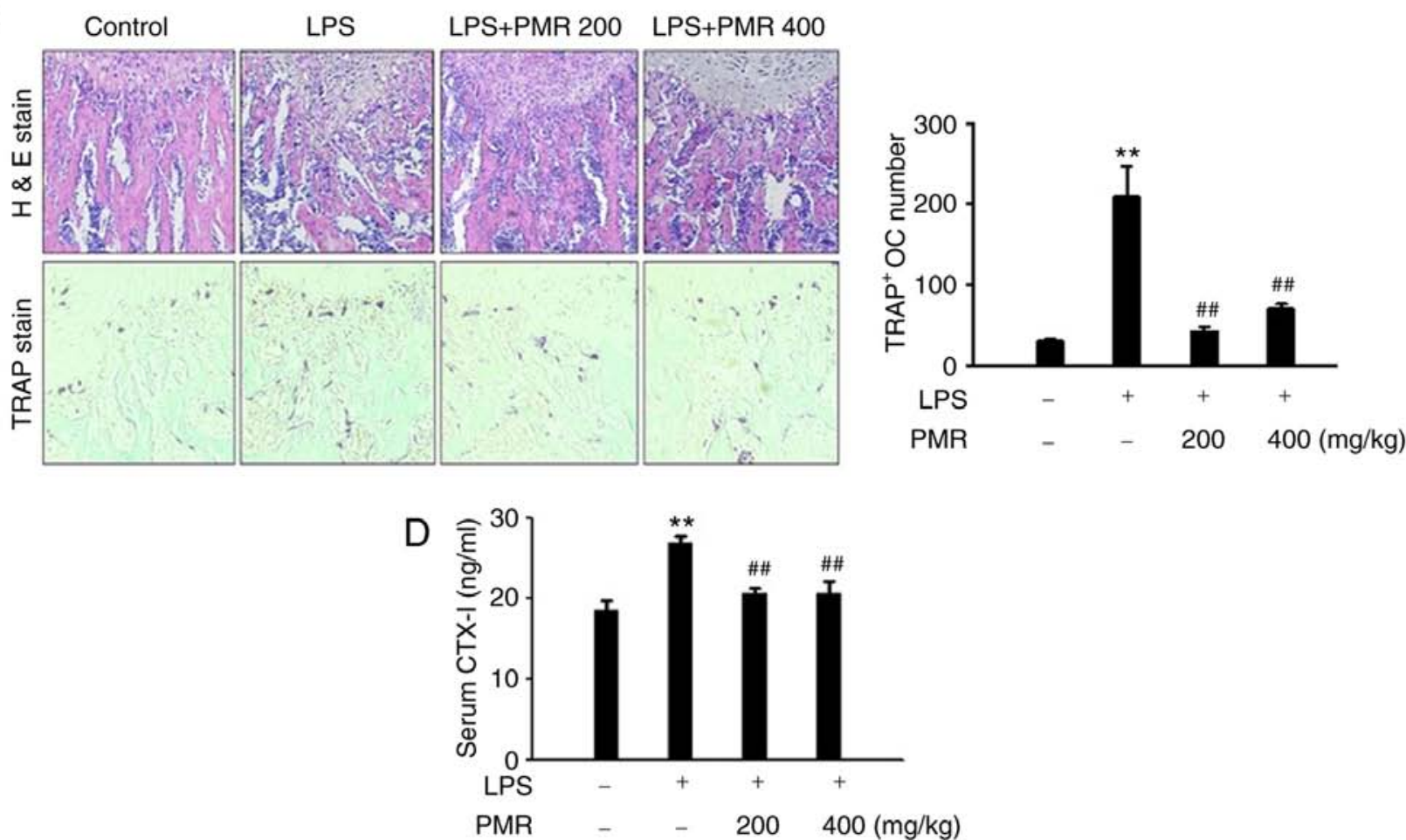

Figure 9. Effect of PMR on LPS-induced bone loss in vivo. (A) Representative three-dimensional reconstruction images of femurs from high-resolution $\mu$ CT analysis. (B) The BV/TV, Tb.Sp, Tb.Th, and Tb.N of the femurs were determined using the $\mu \mathrm{CT}$ data, analyzed by Skyscan 1172 software. (C) Dissected femora were fixed, decalcified, embedded in paraffin and sectioned. Sections were stained with H\&E (upper images) and with TRAP (lower images). The number of osteoclasts per field was counted using the histomorphometric results. (D) Serum levels of CTX-1 were determined using a mouse ELISA kit. ${ }^{*} \mathrm{P}<0.05$, ${ }^{* *} \mathrm{P}<0.01$, ${ }^{* * * *} \mathrm{P}<0.001$ vs. control group; ${ }^{\#} \mathrm{P}<0.05$ and ${ }^{\# \#} \mathrm{P}<0.01$ vs. LPS-treated group. PMR, Polygoni Multiflori Radix; LPS, lipopolysaccharide; $\mu \mathrm{CT}$, micro-computed tomography; BV/TV, trabecular bone volume/total tissue volume; Tb.Sp, trabecular separation; Tb.Th, trabecular thickness; Tb.N, trabecular number; H\&E, hematoxylin and eosin; TRAP, tartrate-acid resistant acid phosphatase. CTX-1, C-teminal telopeptide of type I collagen. 
nized as a serious public health problem afflicting more than 200 million people worldwide. Risk factors of osteoporosis include endocrinological, nutritional and genetic factors, such as hyperparathyroidism and deficiency of estrogen, vitamin D, or calcium (22). Most agents used for treatment and prevention of osteoporosis, such as bisphosphonates, selective estrogen receptor modulators and estrogen, are inhibitors of bone resorption (23). Although these agents are effective, they have several side effects. Therefore, many scientists have been searching for alternative approaches without side effects for the prevention and treatment of osteoporosis through inhibition of osteoclasts and promotion of osteoblasts. The present study demonstrated that PMR inhibited RANKL-induced osteoclast differentiation and stimulated the mineralization activity of osteoblasts.

RANKL is expressed by osteoblastic cells/bone marrow stromal cells; it binds to the RANK receptor on osteoclast precursor cells, and stimulates their differentiation into mature osteoclasts. The RANKL-RANK interaction promotes osteoclast differentiation, which is involved in the formation and survival of osteoclasts (24). In addition, RANKL induces the expression of transcription factors, including c-Fos, and NFATc1, which are essential for osteoclast differentiation $(25,26)$. Previous studies have demonstrated that NFATc1 is a master regulator of osteoclastogenesis, which autoamplifies and induces the expression of osteoclast-specific genes, such as activator protein 1 (AP-1), TRAP, calcitonin receptor, Cathepsin $\mathrm{K}$ and OSCAR, through cooperation with c-Fos $(27,28)$. The present data indicated that PMR significantly inhibited RANKL-induced expression of c-Fos and NFATc1, and consequently, suppressed the mRNA expression of osteoclast-specific gene markers TRAP, OSCAR, Cathepsin K, and Atp6v0d2.

NFATc1 induction is a downstream event to RANKL signaling, which is induced by p38 activation. It may be postulated that this event involves the increase in the transactivation ability of p65 NF- $\mathrm{BB}$ upon Ser-536 phosphorylation by the p38 MAPK $(29,30)$. Because of RANKL stimulation, subsequent ubiquitination and proteasomal degradation of $\mathrm{I} \kappa \mathrm{B}$ occur, and $\mathrm{I} \kappa \mathrm{B}$ releases $\mathrm{NF}-\kappa \mathrm{B}$, which translocates into the nucleus and initiates the transcription of target genes (31). In the present study, PMR inhibited $\mathrm{p} 38$ and $\mathrm{NF}-\kappa \mathrm{B}$ activation induced by RANKL treatment. Specifically, NF- $\kappa$ B transcriptional activity was strongly suppressed following PMR treatment. Thus, the downregulation of NF- $\mathrm{B}$-dependent transcription might be a mechanism by which PMR inhibits RANKL-induced c-Fos and NFATc1 expression during osteoclast differentiation. The mechanism underlying PMR-mediated inhibition of osteoclast differentiation may be related to the reduced expression of osteoclast-specific genes.

Furthermore, PMR treatment stimulated osteoblast differentiation and increased the expression of genes associated with bone formation in primary mouse osteoblasts. ALP activity reflects the early stages of AA/ $\beta$-GP-induced osteogenic differentiation and has a key role in bone mineralization by initiating and/or promoting the formation of hydroxyapatite crystals in the matrix vesicles of osteoblasts (32). Several transcription factors, including ALP, Runx2, osterix and osteocalcin, are prominent osteoblast-specific markers $(33,34)$. Runx2, a key transcription factor for osteogenesis and bone formation, is exclusively expressed in mineralized tissues and osteoblasts. It serves a crucial role in osteoblastogenesis through the induction of major osteoblast-specific genes, including ALP, osteocalcin, and type I collagen $(35,36)$. Specifically, both Runx 2 and osterix have been known as master transcription factors for osteoblast differentiation and for controlling the expression of bone-related genes $(35,37)$. It was reported that Runx2-deficient mice completely lack osteoblasts and bone formation $(38,39)$. Osteocalcin gene expression is initiated during late stages of osteoblast differentiation at the onset of ECM mineralization (40). Thus, the present results demonstrated that PMR enhanced early and late stages of osteoblast differentiation by increasing ALP activity and increasing mineralization, respectively. In addition, PMR treatment increased the expression of osteoblast differentiation markers ALP, Runx2, osterix and osteocalcin. Signaling transduction of osteoblast differentiation specifically occurs through both a canonical Smad-dependent pathway and a non-canonical Smad-independent signaling pathway (such as the p38 MAPK pathway). Both the Smad (Smad 1, 5, and 8) and the p38 MAPK pathways converge at the Runx2 gene to control mesenchymal precursor cell differentiation $(41,42)$. In the present study, PMR treatment induced the phosphorylation of p38 and Smad 1/5/8 and subsequently, stimulated Runx2 expression. Through these actions, PMR enhanced osteoblast differentiation.

LPS promotes osteoclast differentiation, fusion, survival, and activation through the release of RANKL, interleukin (IL)-1, and tumor nexrosis factor (TNF)- $\alpha(43,44)$. LPS was reported to potently stimulate bone resorption in both in vitro and in vivo studies $(45,46)$. Therefore, the LPS-induced bone loss model has become one of the well-established inflammation-mediated osteoporosis models in mice. In a previous study, PMR prevented osteoporosis in an ovariectomized-induced osteoporosis model by increasing bone weight and bone thickness/length ratio, and modulating levels of bone mineral contents, including ALP, phosphorus and femoral calcium $(10,11)$. In the present study, PMR treatment attenuated the LPS-induced trabecular bone loss compared with the LPS-injected group, in BV/TV, Tb.Sp. Despite Tb.N not showing significant differences between the control and LPS-injected groups, PMR treatment resulted in an increased Tb.N in the $400 \mathrm{mg} / \mathrm{kg}$ treatment group. Serum concentration of CTX-1, a bone resorption marker, was lower in the PMR-treated and LPS-injected group compared with the LPS-injected group alone. These findings demonstrated that PMR treatment results in ameliorated LPS-induced bone loss in an in vivo model.

Several phytochemicals including various stilbenes, quinones, flavonoid, phospholipids and other compounds have been identified in PMR. Phytochemicals emodin (a quinone) and THS (a stilbene) are main characteristic components extracted from the PMR (9). Recently, a study reported that emodin modulated bone remodeling by inhibiting RANKL-induced osteoclast differentiation in BMMs and stimulated osteoblast formation on primary osteoblast cells (47). THS has been extracted from the roots of Polygonum multiflorum Thunb. and has been reported to promote bone mineral density and bone strength in the femoral bones of rats. The present study identified emodin and THS 
as PMR components. These results suggested that the complementary effect of these components of PMR may contribute to the inhibitory effect of PMR on RANKL-induced osteoclast differentiation and its stimulatory effect on osteoblast formation.

In conclusion, PMR treatment inhibited RANKL-induced NF- $\mathrm{kB}$ transcriptional activity via the p38 and ERK signaling pathways, and this downregulation of NF- $\mathrm{kB}$ was involved in the inhibitory effect of PMR on RANKL-induced c-Fos and NFATc1 during osteoclast differentiation. Furthermore, PMR treatment increased ALP and mineralization activity, and elevated markers of osteoblast differentiation Runx2, ALP, osterix and osteocalcin, in mouse calvarial primary osteoblasts. Finally, PMR reduced the LPS-mediated bone loss in an in vivo model. PMR may modulate bone metabolism via dual actions of reducing osteoclast differentiation and stimulating osteoblast formation. Taken together, PMR might be an effective natural product for the treatment of bone diseases.

\section{Acknowledgements}

Not applicable.

\section{Funding}

The present study was supported by Wonkwang University in 2016.

\section{Availability of data and materials}

The analyzed datasets generated during the study are available from the corresponding author on reasonable request.

\section{Author's contributions}

SYH and YKK conceived and designed the experiments. SYH and KHL performed the experiments. SYH performed the analysis and interpretation of data. SYH and YKK were responsible for writing, review and/or revision of the manuscript.

\section{Ethics approval and consent to participate}

All animal experiments were approved by the Institutional Animal Care and Use Committee of Wonkwang University (approval no. WKU15-143).

\section{Consent for publication}

Not applicable.

\section{Competing interests}

The authors declare that they have no competing interests.

\section{References}

1. Shaw AT and Gravallese EM: Mediators of inflammation and bone remodeling in rheumatic disease. Semin Cell Dev Biol 49: $2-10,2016$
2. Nagao M, Feinstein TN, Ezura Y, Hayata T, Notomi T, Saita Y, Hanyu R, Hemmi H, Izu Y, Takeda S, et al: Sympathetic control of bone mass regulated by osteopontin. Proc Natl Acad Sci USA 108: 17767-17772, 2011

3. Florencio-Silva R, Sasso GR, Sasso-Cerri E, Simoes MJ and Cerri PS: Biology of bone tissue: Structure, function, and factors that influence bone cells. Biomed Res Int 2015: 421746, 2015.

4. Komori T: Regulation of osteoblast differentiation by transcription factors. J Cell Biochem 99: 1233-1239, 2006.

5. Suda T, Takahashi N, Udagawa N, Jimi E, Gillespie MT and Martin TJ: Modulation of osteoclast differentiation and function by the new members of the tumor necrosis factor receptor and ligand families. Endocr Rev 20: 345-357, 1999.

6. Takayanagi H: Osteoimmunology: Shared mechanisms and crosstalk between the immune and bone systems. Nat Rev Immunol 7: 292-304, 2007.

7. Takayanagi H, Kim S, Koga T, Nishina H, Isshiki M, Yoshida H, Saiura A, Isobe M, Yokochi T, Inoue J, et al: Induction and activation of the transcription factor NFATc1 (NFAT2) integrate RANKL signaling in terminal differentiation of osteoclasts. Dev Cell 3: 889-901, 2002

8. Kim K, Kim JH, Lee J, Jin HM, Lee SH, Fisher DE, Kook H, Kim KK, Choi Y and Kim N: Nuclear factor of activated T cells $\mathrm{cl}$ induces osteoclast-associated receptor gene expression during tumor necrosis factor-related activation-induced cytokine-mediated osteoclastogenesis. J Biol Chem 280: 35209-35216, 2005.

9. Lin L, Ni B, Lin H, Zhang M, Li X, Yin X, Qu C and Ni J: Traditional usages, botany, phytochemistry, pharmacology and toxicology of Polygonum multiflorum Thunb: A review. J Ethnopharmacol 159: 158-183, 2015.

10. Kim MJ, Seo BI, Shin SS and Park JH: Effect of Polygoni multiflori Radix and cynanchi wilfordii Radix on prevention of osteoporosis in ovariectomized rats. Kor J Herbol 19: 23-34, 2004.

11. Do YJ, Ku SK, Kim HT, Oh T, Cho YM, Kim SW, Ryu IS and Lee KW: Antiosteoporotic effects of Polygoni Multiflori Radix (PMR) in ovariectomized (OVX)-induced osteoporosis in ddY mice. J Vet Clin 28: 375-386, 2011.

12. Kim JY, Baek JM, Ahn SJ, Cheon YH, Park SH, Yang M, Choi MK and Oh J: Ethanolic extract of Schizonepeta tenuifolia attenuates osteoclast formation and activation in vitro and protects against lipopolysaccharide-induced bone loss in vivo. BMC Complement Altern Med 16: 301, 2016.

13. Ha H, Shim KS, Kim T, An H, Lee CJ, Lee KJ and Ma JY: Water extract of Acer tegmentosum reduces bone destruction by inhibiting osteoclast differentiation and function. Molecules 19: 3940-3954, 2014

14. Rho TW, Lee SY, Han SY, Kim JH, Lee KH, Kim DS, Kwak HB and Kim YK: Glycyrrhizae Radix inhibits osteoclast differentiation by inhibiting c-Fos-dependent NFATc1 expression. Am J Chin Med 45: 283-298, 2017.

15. Livak KJ and Schmittgen TD: Analysis of relative gene expression data using real-time quantitative PCR and the $2^{-\Delta \Delta C_{\mathrm{T}}}$ method. Methods 25: 402-408, 2001.

16. Sharma-Bhandari A, Park SH, Kim JY, Oh J and Kim Y: Lysyl oxidase modulates the osteoblast differentiation of primary mouse calvaria cells. Int J Mol Med 36: 1664-1670, 2015.

17. Song J, Jing Z, Hu W, Yu J and Cui X: $\alpha$-Linolenic acid inhibits receptor activator of $\mathrm{NF}-\kappa \mathrm{B}$ ligand induced (RANKL-induced) osteoclastogenesis and prevents inflammatory bone loss via downregulation of nuclear Factor-KappaB-inducible nitric oxide synthases (NF-kB-iNOS) signaling pathways. Med Sci Monit 23: 5056-5069, 2017.

18. Kim JY,Park SH, Baek JM, Erkhembaatar M, Kim MS, Yoon KH, Oh $\mathrm{J}$ and Lee MS: Harpagoside inhibits RANKL-induced osteoclastogenesis via Syk-Btk-PLC $\gamma 2-\mathrm{Ca}^{2+}$ signaling pathway and prevents Inflammation-mediated bone loss. J Nat Prod 78: 2167-2174, 2015.

19. Feng X: RANKing intracellular signaling in osteoclasts. IUBMB Life 57: 389-395, 2005.

20. Naylor K and Eastell R: Bone turnover markers: Use in osteoporosis. Nat Rev Rheumatol 8: 379-389, 2012.

21. Hofbauer LC: From bone cell biology to novel therapies of osteoporosis. Drug Res 65 (Suppl 1): S14-S15, 2015.

22. Chau DL, Edelman SV and Chandran M: Osteoporosis and diabetes. Curr Diab Rep 3: 37-42, 2003.

23. Nardone V, D'Asta F and Brandi ML: Pharmacological management of osteogenesis. Clinics 69: 438-446, 2014 
24. Boyce BF and Xing L: Functions of RANKL/RANK/OPG in bone modeling and remodeling. Arch Biochem Biophys 473: 139-146, 2008.

25. Kang MR, Jo SA, Yoon YD, Park KH, Oh SJ, Yun J, Lee CW, Nam KH, Kim Y, Han SB, et al: Agelasine D suppresses RANKL-induced osteoclastogenesis via down-regulation of c-Fos, NFATc1 and NF-kB. Mar Drugs 12: 5643-5656, 2014.

26. Kong L, Zhao Q, Wang X, Zhu J, Hao D and Yang C: Angelica sinensis extract inhibits RANKL-mediated osteoclastogenesis by down-regulated the expression of NFATc1 in mouse bone marrow cells. BMC Complement Altern Med 14: 481, 2014.

27. Asagiri M, Sato K, Usami T, Ochi S, Nishina H, Yoshida H, Morita I, Wagner EF, Mak TW, Serfling E, et al: Autoamplification of NFATc1 expression determines its essential role in bone homeostasis. J Exp Med 202: 1261-1269, 2005.

28. Ikeda F, Nishimura R, Matsubara T, Tanaka S, Inoue J, Reddy SV Hata K, Yamashita K, Hiraga T, Watanabe T, et al: Critical roles of c-Jun signaling in regulation of NFAT family and RANKL-regulated osteoclast differentiation. J Clin Invest 114: 475-484, 2004

29. Huang H, Ryu J, Ha J, Chang EJ, Kim HJ, Kim HM, Kitamura T, Lee ZH and Kim HH: Osteoclast differentiation requires TAK1 and MKK6 for NFATc1 induction and NF-kappaB transactivation by RANKL. Cell Death Differ 13: 1879-1891, 2006.

30. Iotsova V, Caamaño J, Loy J, Yang Y, Lewin A and Bravo R: Osteopetrosis in mice lacking NF-kappaB1 and NF-kappaB2. Nat Med 3: 1285-1289, 1997.

31. Hayden MS and Ghosh S: Signaling to NF-kappaB. Genes Dev 18: 2195-2224, 2004

32. Orimo $\mathrm{H}$ and Shimada T: The role of tissue-nonspecific alkaline phosphatase in the phosphate-induced activation of alkaline phosphatase and mineralization in SaOS-2 human osteoblast-like cells. Mol Cell Biochem 315: 51-60, 2008.

33. Karsenty G: Transcriptional control of skeletogenesis. Annu Rev Genomics Hum Genet 9: 183-196, 2008.

34. Lian JB, Stein GS, Javed A, van Wijnen AJ, Stein JL, Montecino M, Hassan MQ, Gaur T, Lengner CJ and Young DW: Networks and hubs for the transcriptional control of osteoblastogenesis. Rev Endocr Metab Disord 7: 1-16, 2006.

35. Ducy P, Zhang R, Geoffroy V, Ridall AL and Karsenty G: Osf2/Cbfa1: A transcriptional activator of osteoblast differentiation. Cell 89: 747-754, 1997.

36. Franceschi RT and Xiao G: Regulation of the osteoblast-specific transcription factor, Runx2: Responsiveness to multiple signal transduction pathways. J Cell Biochem 88: 446-454, 2003.

37. Cancedda R, Castagnola P, Cancedda FD, Dozin B and Quarto R Developmental control of chondrogenesis and osteogenesis. Int J Dev Biol 44: 707-714, 2000.

38. Komori T, Yagi H, Nomura S, Yamaguchi A, Sasaki K, Deguchi K, Shimizu Y, Bronson RT, Gao YH, Inada M, et al: Targeted disruption of $C b f a l$ results in a complete lack of bone formation owing to maturational arrest of osteoblasts. Cell 89: 755-764, 1997.
39. Otto F, Thornell AP, Crompton T, Denzel A, Gilmour KC, Rosewell IR, Stamp GW, Beddington RS, Mundlos S, Olsen BR, et al: Cbfal, a candidate gene for cleidocranial dysplasia syndrome, is essential for osteoblast differentiation and bone development. Cell 89: 765-771, 1997.

40. Lian JB, Stein GS, Stein JL and van Wijnen AJ: Osteocalcin gene promoter: Unlocking the secrets for regulation of osteoblast growth and differentiation. J Cell Biochem Suppl 30-31: 62-72, 1998.

41. Chen G, Deng C and Li YP: TGF- $\beta$ and BMP signaling in osteoblast differentiation and bone formation. Int J Biol Sci 8: 272-288, 2012

42. Lee KS, Kim HJ, Li QL, Chi XZ, Ueta C, Komori T, Wozney JM, Kim EG, Choi JY, Ryoo HM and Bae SC: Runx2 is a common target of transforming growth factor beta 1 and bone morphogenetic protein 2, and cooperation between Runx2 and Smad5 induces osteoblast-specific gene expression in the pluripotent mesenchymal precursor cell line C2C12. Mol Cell Biol 20: 8783-8792, 2000.

43. Islam S, Hassan F, Tumurkhuu G, Dagvadorj J, Koide N, Naiki Y, Mori I, Yoshida T and Yokochi T: Bacterial lipopolysaccharide induces osteoclast formation in RAW 264.7 macrophage cells. Biochem Biophys Res Commun 360: 346-351, 2007.

44. Mörmann M, Thederan M, Nackchbandi I, Giese T, Wagner C and Hänsch GM: Lipopolysaccharides (LPS) induce the differentiation of human monocytes to osteoclasts in a tumour necrosis factor (TNF) alpha-dependent manner: A link between infection and pathological bone resorption. Mol Immunol 45: 3330-3337, 2008.

45. Ishihara $Y$, Nishihara $T$, Maki E, Noguchi $T$ and Koga T: Role of interleukin-1 and prostaglandin in in vitro bone resorption induced by Actinobacillus actinomycetemcomitans lipopolysaccharide. J Periodontal Res 26: 155-160, 1991.

46. Orcel P, Feuga M, Bielakoff J and De Vernejoul MC: Local bone injections of LPS and M-CSF increase bone resorption by different pathways in vivo in rats. Am J Physiol 264: E391-E397, 1993.

47. Kim JY, Cheon YH, Kwak SC, Baek JM, Yoon KH, Lee MS and $\mathrm{Oh} \mathrm{J}$ : Emodin regulates bone remodeling by inhibiting osteoclastogenesis and stimulating osteoblast formation. J Bone Miner Res 29: 1541-1553, 2014.

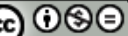

This work is licensed under a Creative Commons Attribution-NonCommercial-NoDerivatives 4.0 International (CC BY-NC-ND 4.0) License. 